\title{
Research Paper \\ The Effect of Competitiveness on Economic Performance in Selected Developing and Developed Countries
}

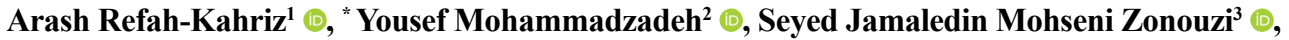 \\ Nayyer Hashemi Berenjabadi ${ }^{1} \mathbb{0}$, Negar Ghasemzadeh ${ }^{1}$
}

1. MA, Department of Economics, Faculty of Economics and Management, Urmia University, Urmia, Iran.

2. PhD. in Economics, Assistant Professor of Economics, Department of Economics, Faculty of Economics and Management, Urmia University, Urmia, Iran.

3. PhD. in Economics, Assistant Professor of Economics, Department of Economics, Faculty of Economics and Management, Urmia University, Urmia, Iran.

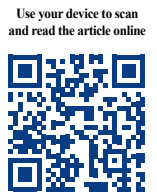

dtation: Refah-Kahriz, A., Mohammadzadeh, Y., Mohseni Zonouzi, S. J., Hashemi Berenjabadi, N., \& Ghasemzadeh, N. (2019). [The Effect of Competitiveness on Economic Performance in Selected Developing and Developed Countries (Persian)]. Quarterly Journal of the Macro and Strategic Policies, 7(1), 86-107. https://doi.org/10.32598/JMSP.7.1.86

https://doi.org/10.32598/JMSP.7.1.86

Received: 08 Sep 2017

Accepted: 17 Sep 2018

Available Online: 01 Apr 2019

Key words:

Education, Self-care, General health, Vulnerable women

\begin{abstract}
A B S TRACT
Self-care is a valuable step in preventing and controlling the high-risk sexual behaviors leading to sexually transmitted diseases, and ultimately improving the general health of vulnerable women in society. This study aimed to determine the effect of self-care education on the general health status of vulnerable women. The current field trial study was conducted in 2011-2012, in vulnerable women referring to counseling centers affiliated with provincial support service centers in Isfahan City, Iran. A total of 64 women were selected according to the inclusion criteria and were randomly assigned to the intervention and control groups. The required data were collected using a demographic data questionnaire and general health standard tool. The obtained data were analyzed using descriptive and analytical statistics. The obtained results indicated no significant difference in the mean general health pretest scores of intervention and control groups in general health domains $(\mathrm{P}>0.05)$. However, immediately and three months after the implementation of the general healthcare program, the mean general health scores of all domains significantly reduced in the intervention group, compared to the controls $(\mathrm{P}<0.05)$. The implementation of Orem's self-care educational program can play a role in promoting the general health of vulnerable women in terms of biosocial aspects, as well as anxiety and depression. It is suggested that this program be used in healthcare centers for vulnerable populations. JEL Classification: C33, F43, O11, O47
\end{abstract}

* Corresponding Author:

Yousef Mohammadzadeh, PhD.

Address: Department of Economics, Faculty of Economics and Management, Urmia University, Urmia, Iran.

Tel: +98 (914) 9180019

E-mail: yo.mohammadzadeh@urmia.ac.ir 


\section{تأثير رقابتيذيرى بر عملكرد اقتصادى در كشورهاى منتخب در حال توسعه و توسعديافته}

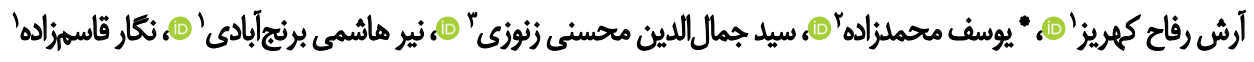

ا - كارشناس ارشد، كروه اقتصاد، دانشكده اقتصاد و مديريت، داتشكاه اروميه، الروميه، ايران.

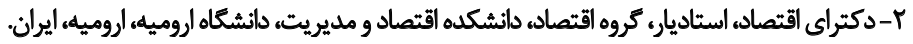

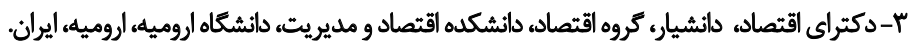

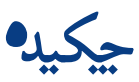

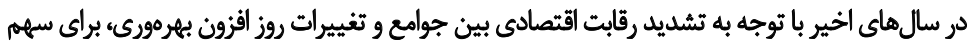

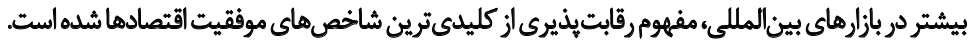

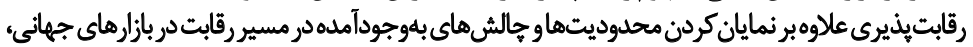

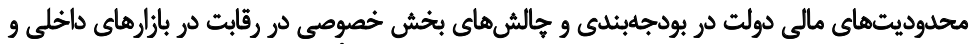

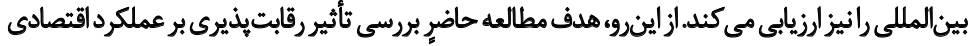

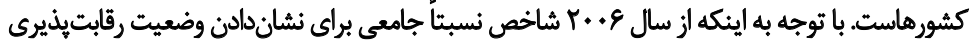

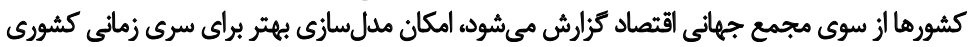

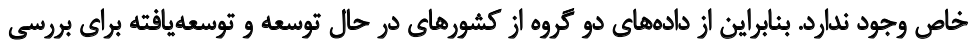

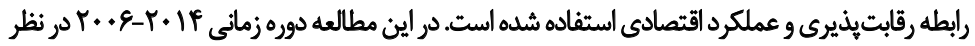

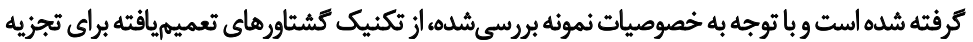

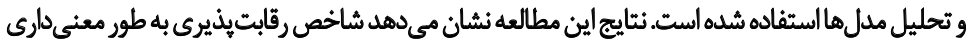

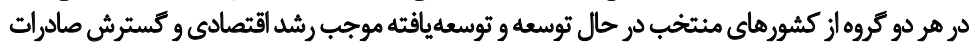

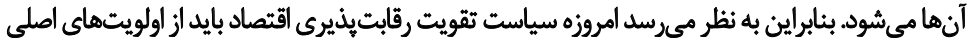

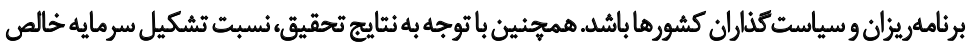

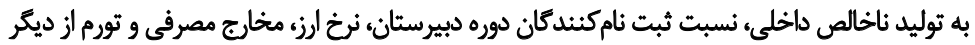

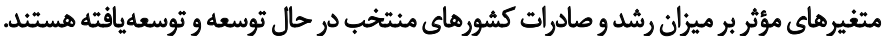
طبقدبندى C33, F43, O11, O47 : JEL

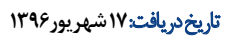

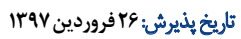

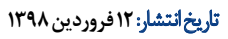

كليدوإوها:

رقابت يذيرى، رشد ريد اقتصادى، صادرات. روش كشتاورهاى تعميميافته

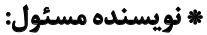

دكتر يوسف محمدزاده

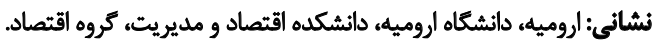

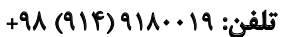

بست الكترونيكى: yo.mohammadzadeh@urmia.ac.ir 


\section{مقدمه}

رشد بالاى اقتصادى و توسعه بهتر اقتصادى از جمله اهدافى است كه همه اقتصادها به دنبال آن هستند. دليل

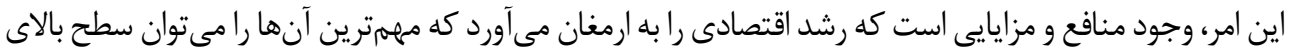

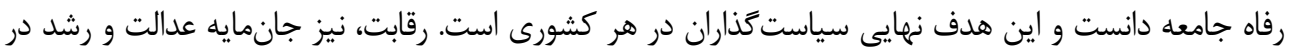

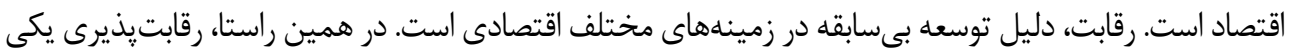

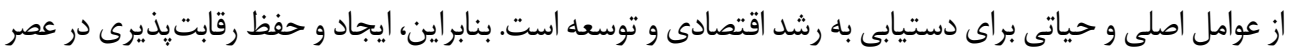

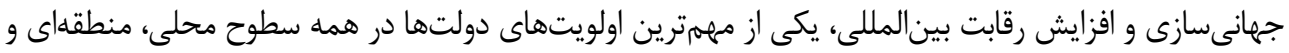

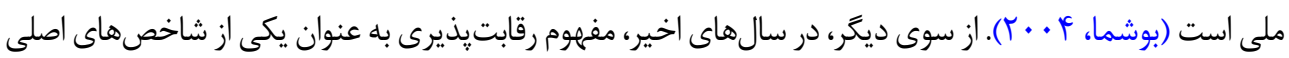
يشرفت اقتصادى مطرح شده است.

رقابتيذيرى در حالى كه محدوديتها و جالشهاى بلوجودآمده در مسير رقابت در بازارهاى جهانى را نمايان

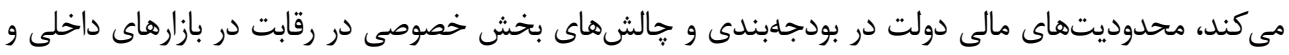

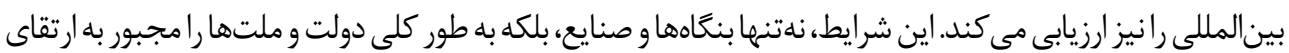

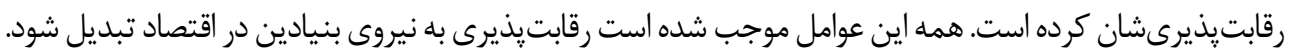

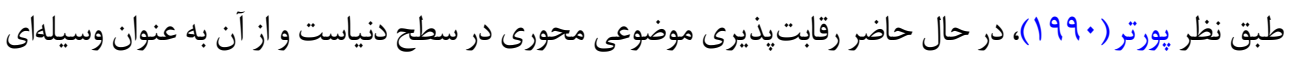

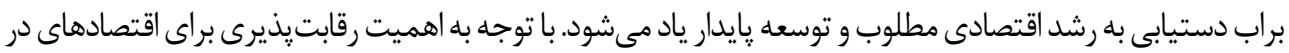

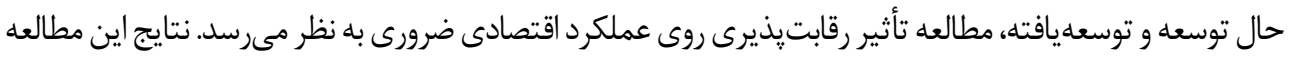

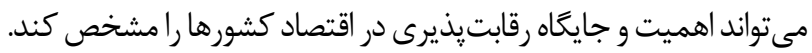
منظور از عملكرد اقتصاد در مرحله اول، رشد اقتصادى است و با توجه به اهميت صادرات در رشد توليد ملى، به

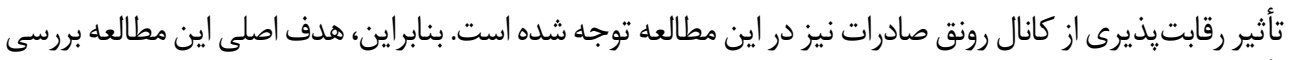

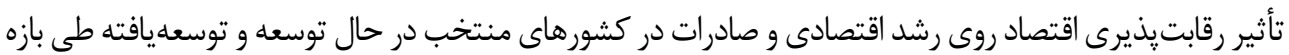

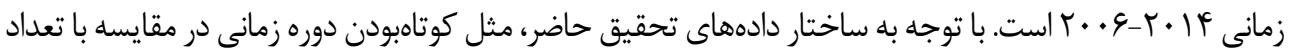

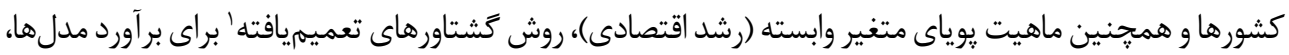

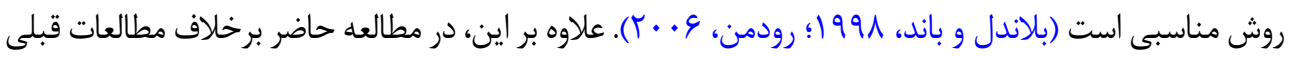

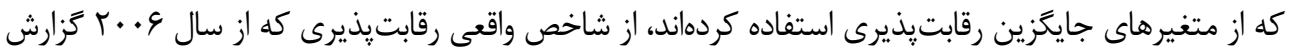
مىشود، استفاده شده است.

در ادامه ساختار مقاله بدين صورت است كه در بخش دوم، ادبيات موضوع و مرورى بر بيشينه مطالعات انجامشده

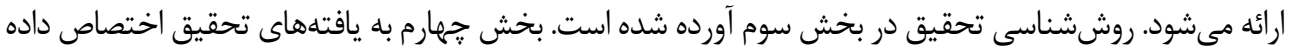

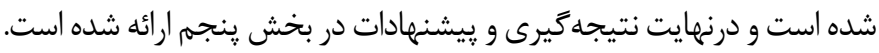


|- إيبات موضوع

\section{|- |- شاخُص رقابت يُذيرى}

امروزه، بنعاههاى اقتصادى بدون فروش در سطح جهانى و توليد فرامليتى، امكان رويارويى با رقباى خود را تقريباًاز

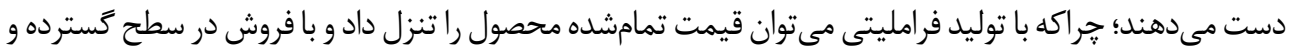

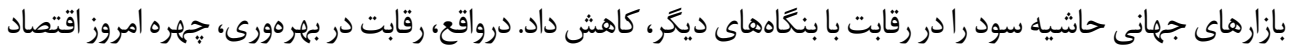

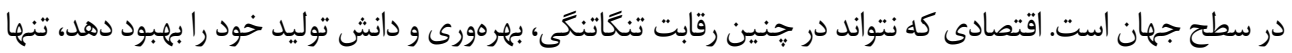

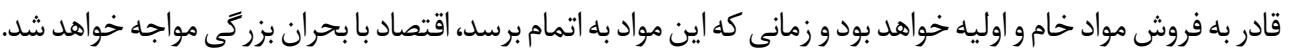
به دليل اهميت ويزه اين مسئله، اخيراً شاخص رقابتٍذيرى جهانى ' مطرح شده است كه مجمع جهانى

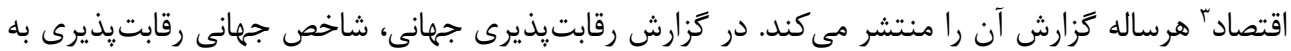

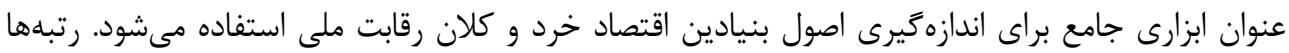

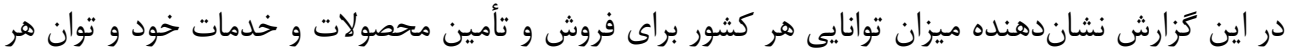

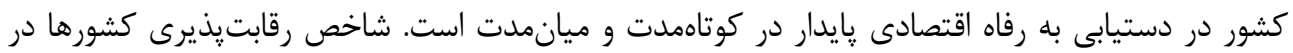

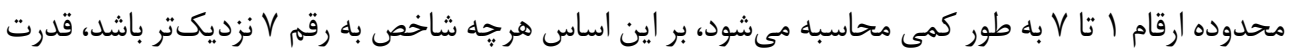

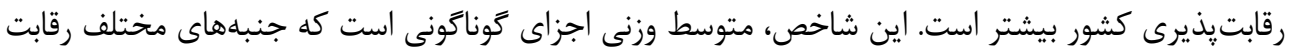

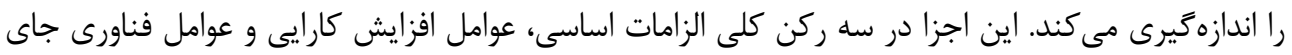

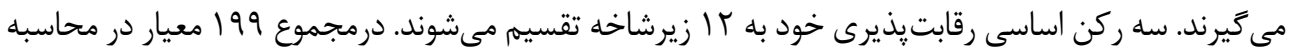

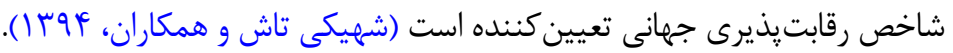

مطالعات متعددى با استفاده از شاخصهاى رقابت يذيرى وضعيت اقتصادها را بررسى كردهاند. از جمله مير احسنى

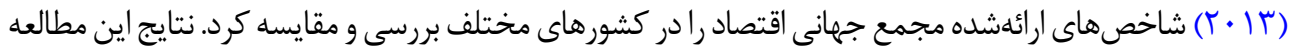

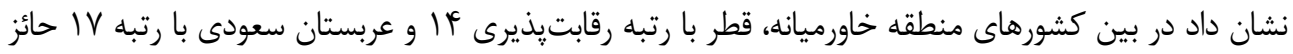

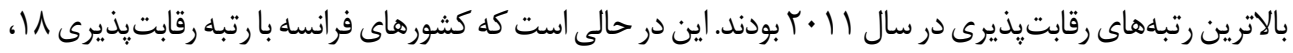

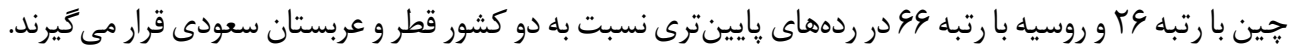

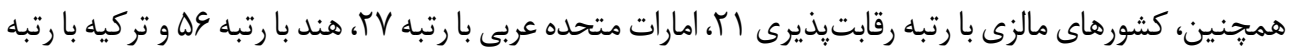

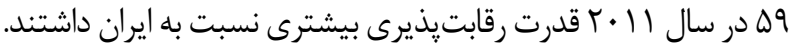

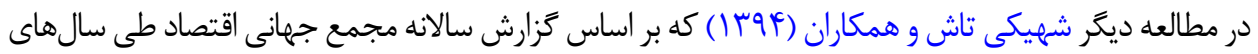

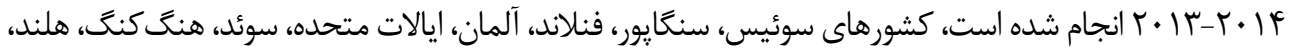

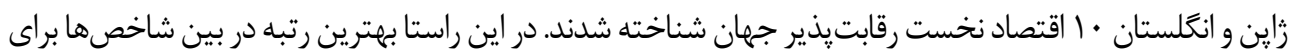

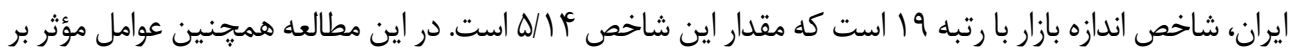

2. Global Competitiveness Index (GCI)

3. World Economic Forum (WEF) 
شاخص رقابت يذيرى بررسى شدهاند.

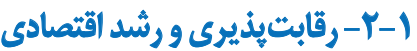

مبناى نظرى ارتباط بين رقابتيذيرى و رشد اقتصادى رابايد در فرايند توسعه جستوجو كرد. بر اساس تئورى هاى

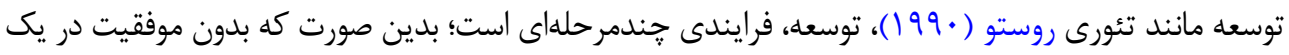

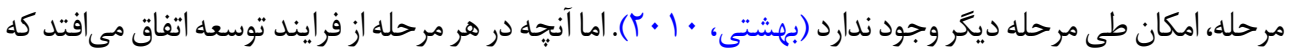

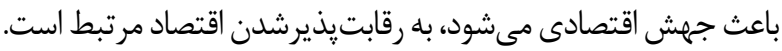

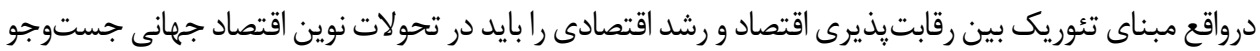

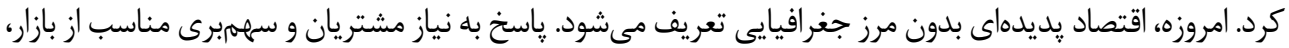

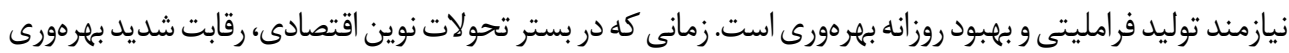

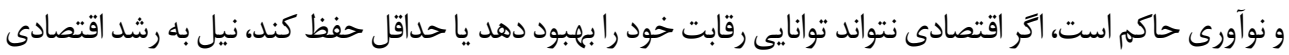

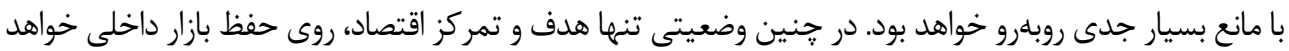

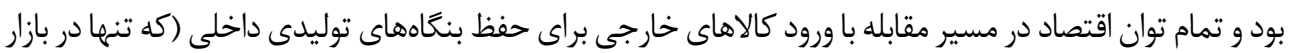

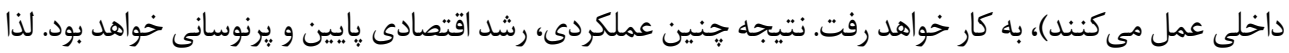

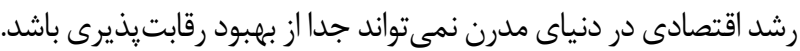

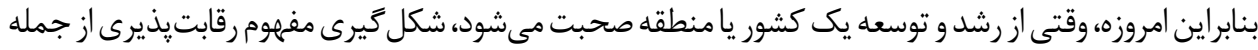

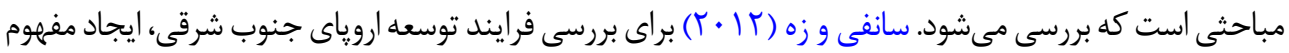

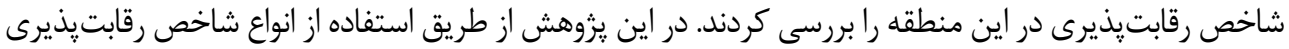

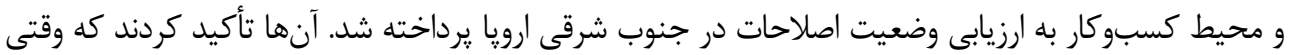

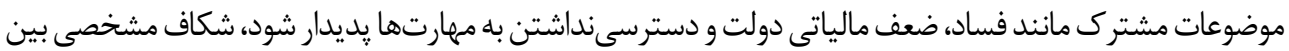

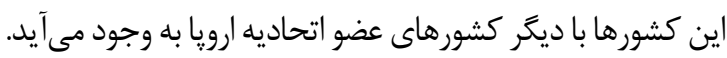

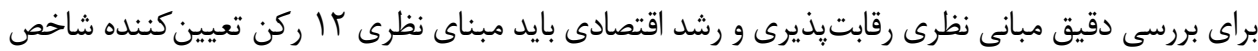

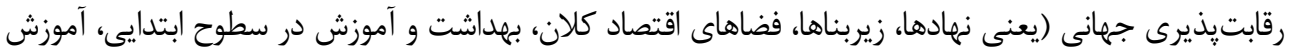

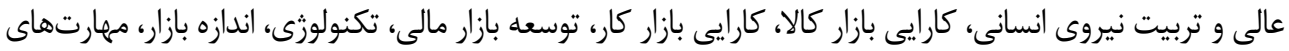

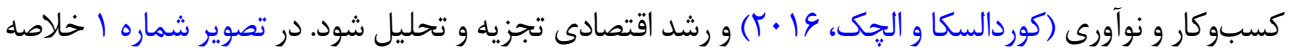
اركان شاخص رقابت يذيرى گزارش شده است

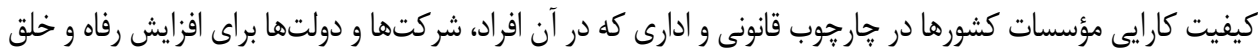

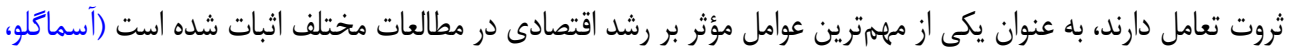

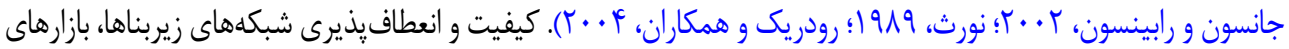

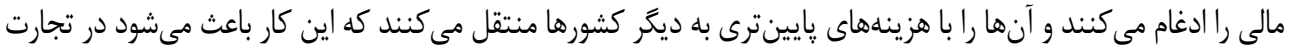




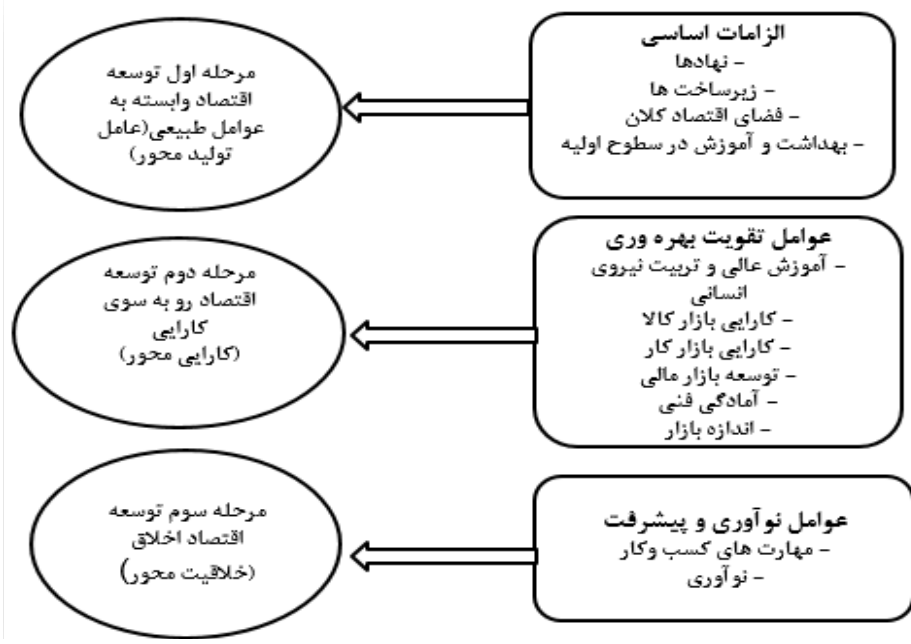

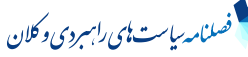

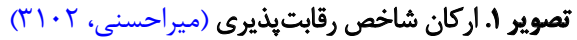

بينالملل، كالاو خدمات به طور ايمن و بهموقع به بازارها عرضه شوند. بنابر اين تعيين محل فعاليتهاى اقتصادى، تسهيلات

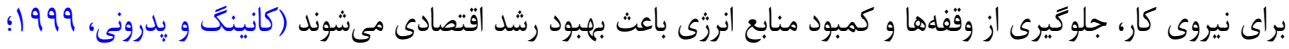

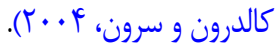

علاوه بر اين، بازبودن تجارت در بازارهاى رقابتى بينالمللى كشورها راقادر مى كند تااز طريق تجارت و سرمايهَذارى

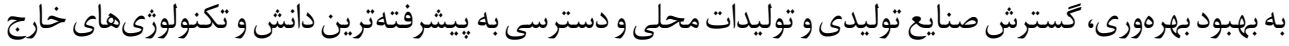

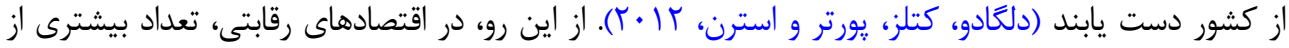

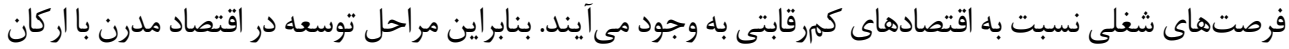

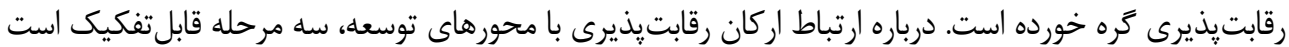

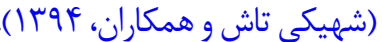 \\ r - - سطح نهادهمحور}

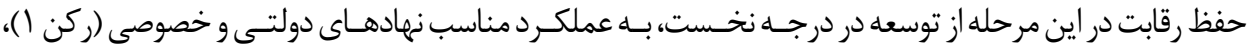

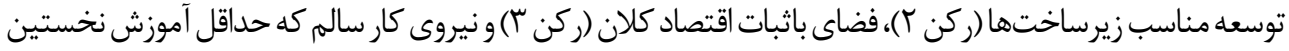

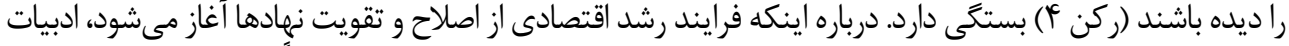

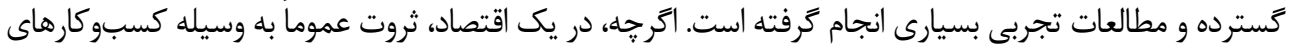

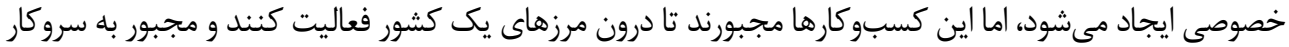

\section{Factor-Driven Stage}


داشتن با نهادهايى هستند كه دولت آن كشور ايجاد و حفظشان مى كند. تحقيقات اقتصادى امروزه تلاش مى كنند تا

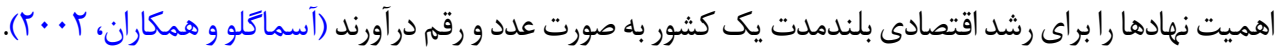

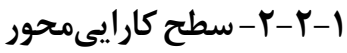

بهرهورى اقتصادى كه در مرحله بالاترى از رقابت قرار دارد، با بالارفتن درجه توسعهيافتگى، افزايش مىيابد و

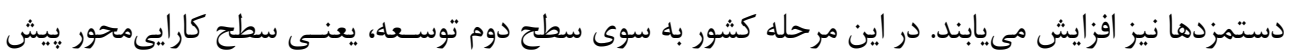

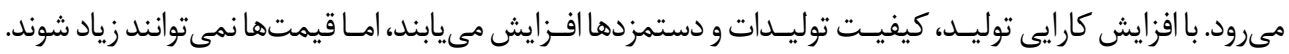

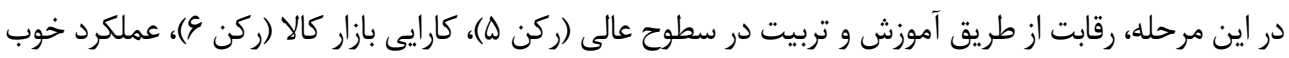

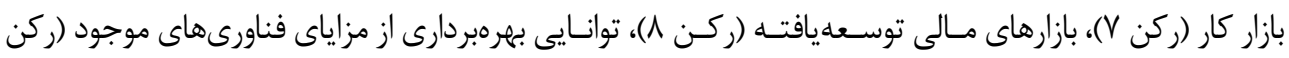

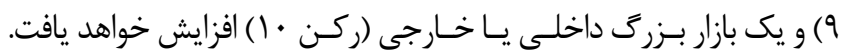

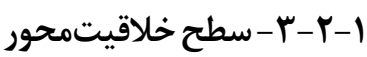

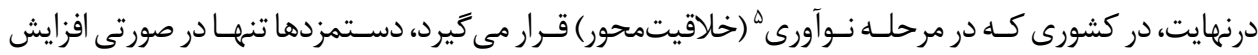

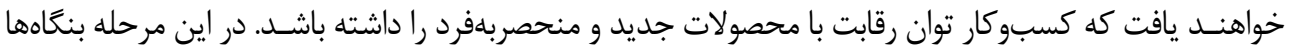

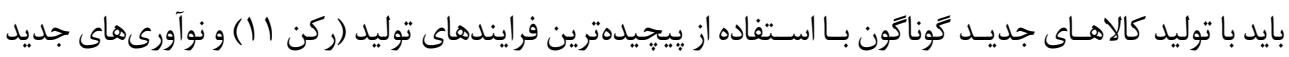

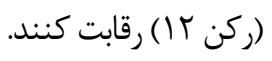

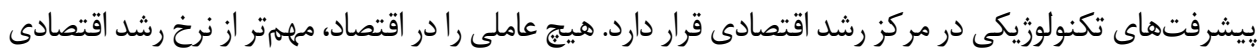

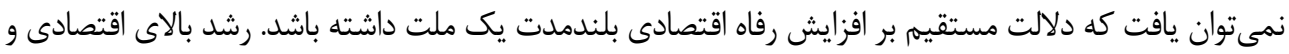

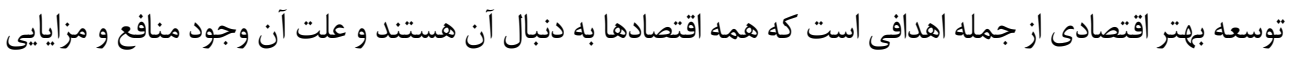

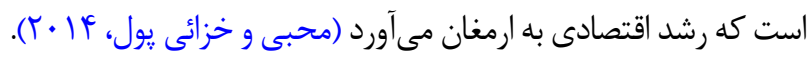

بنابر اين، داشتن نهادهاى كار آمد، بهبود بهرهورى و بروز مداوم خلاقيت و نوآورى كه يايههاى رقابتيذيرى را را شكل

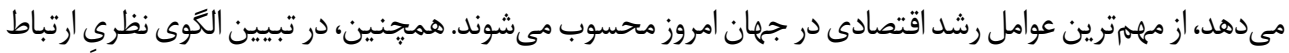

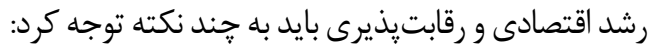

-مفهوم رقابتٍذيرى در سير تكوينى نظريات مزيت نسبى و مزيت نسبى يويادر جهان امروز مورد توجه اقتصاددانان در حوزه تجارت قرار گرفته است.

- مطالعه رويكردهاى مختلف الكوى رشد درونزا، بيانكر اين مطلب است كه بسيارى از اين عوامل در مطالعات رشد درونزا به صورت يك مؤلفه وارد مدل رشد شده است تا توضيحدهندكى بيشترى را براى رشد اقتصادى ايجاد كند. - در بيشتر موارد شاخصهاى تركيبى رقابتيذيرى، بر اساس عوامل تعيين كننده آن دستهبندى شدهاند.بر اين

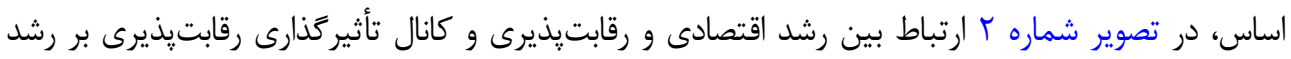




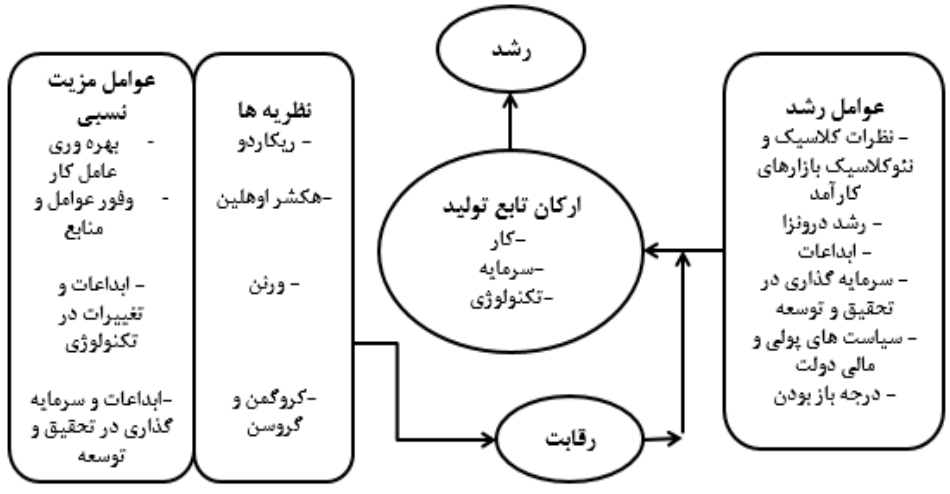

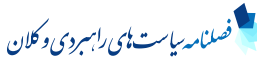

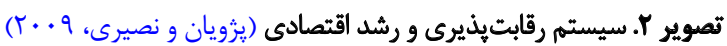

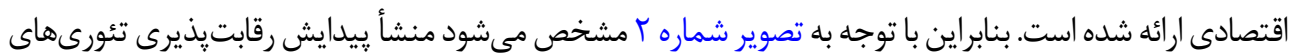

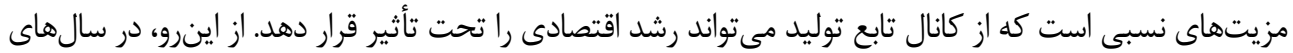

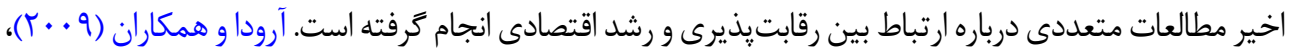

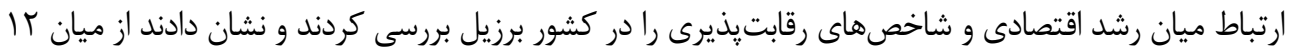

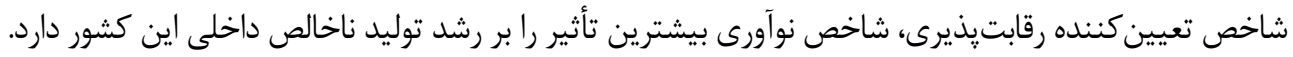

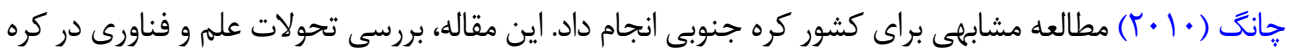

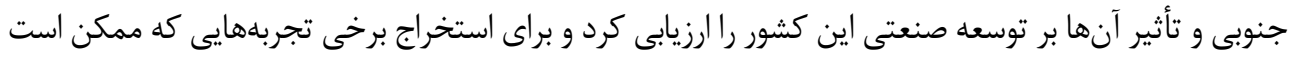
بعدها قابل اجرا باشد، تلاش كرد.

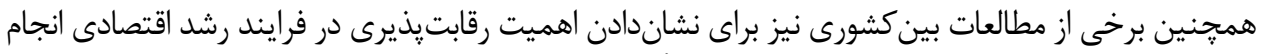

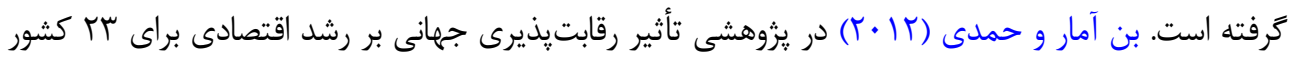

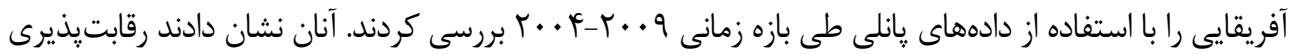

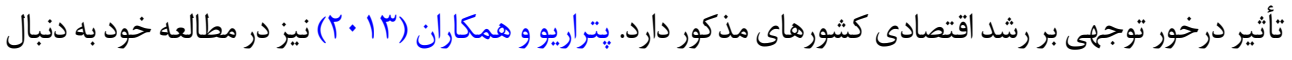

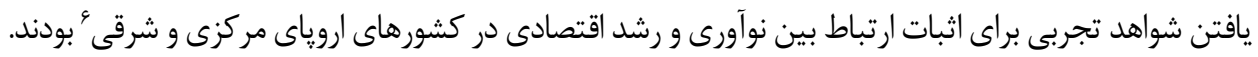

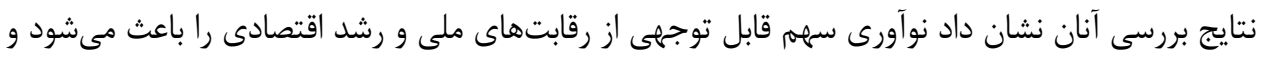

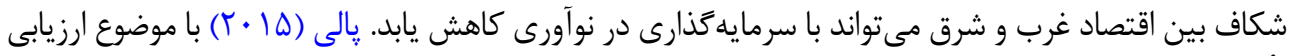

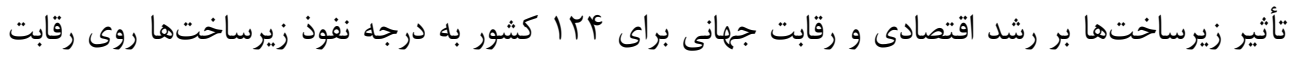

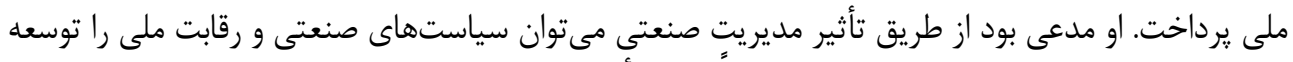

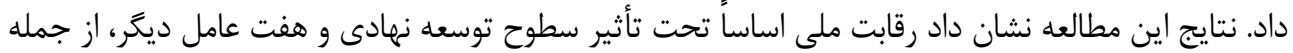

6. Central and Eastern Europe (CEE) 


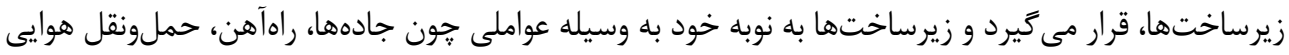

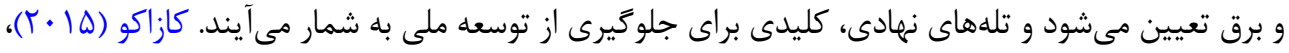

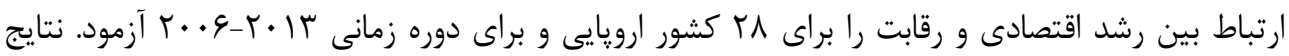

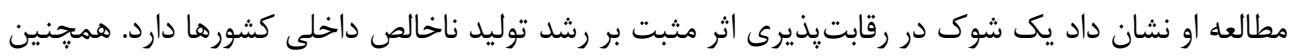

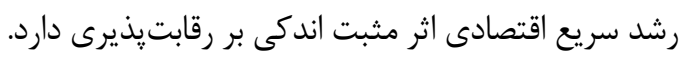

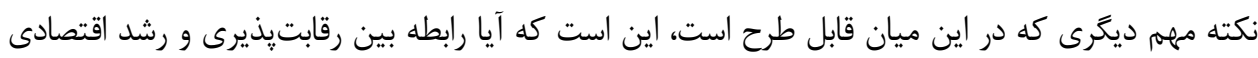

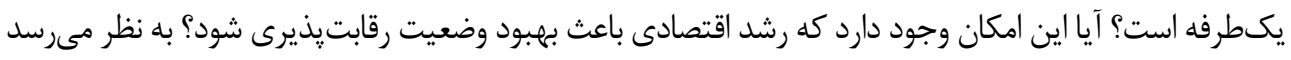

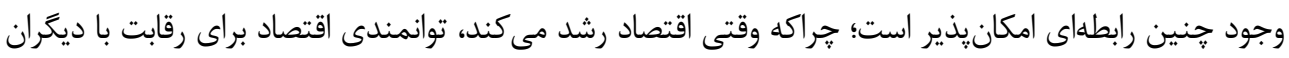

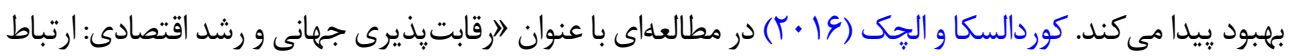

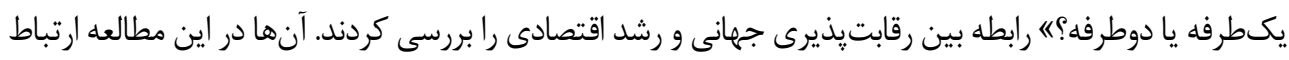

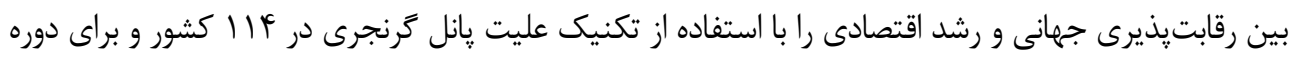

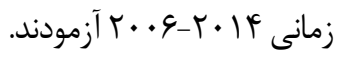

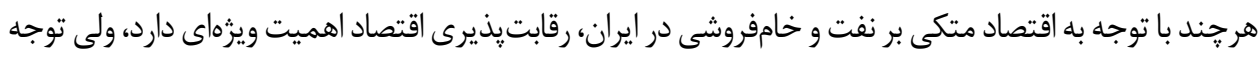

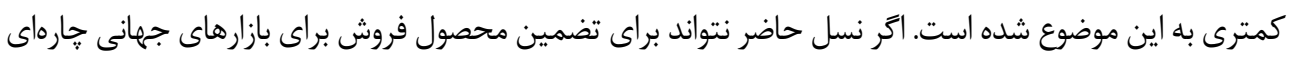

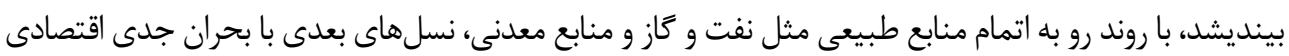

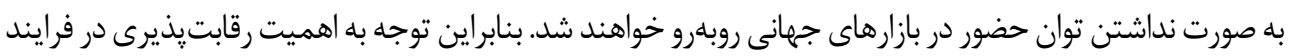
رشد و توسعه اقتصادى از ضروريات امروز مباحث اقتصادى در در ايران است.

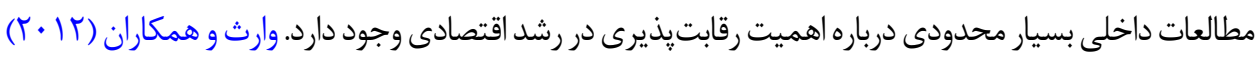

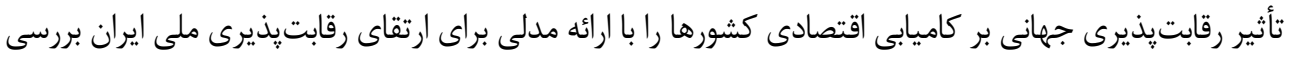

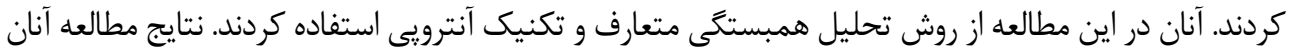

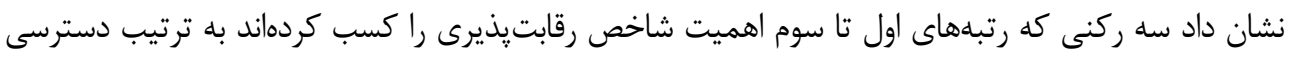

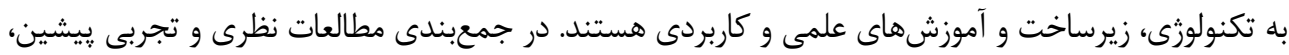

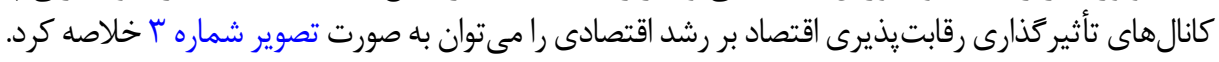

\section{|-" رقابتيذيرى و صادرات}

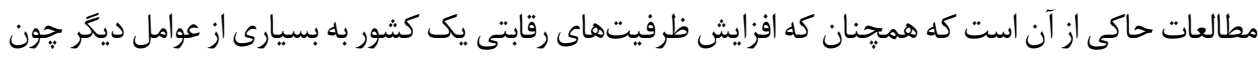

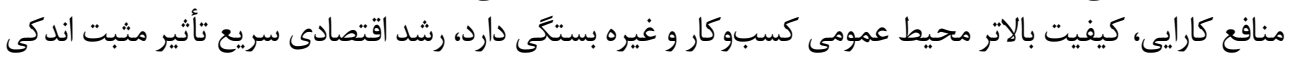

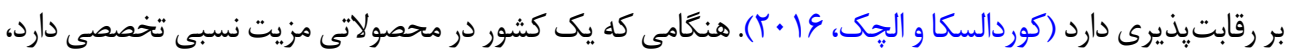

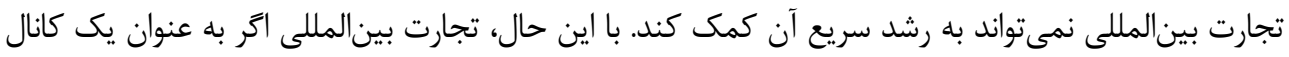

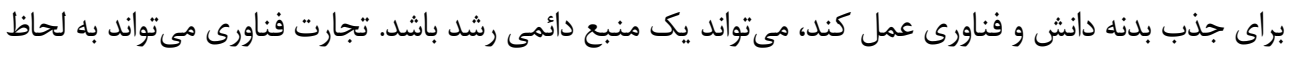

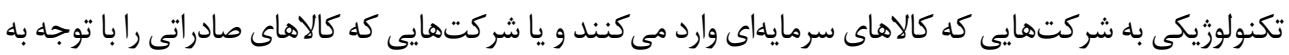




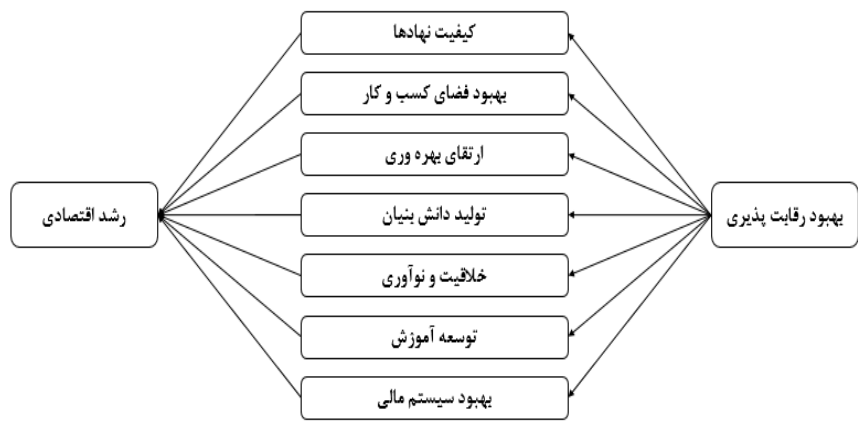

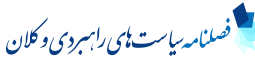

تصوير r. كانالهاى تأثيركذارى رقابتيذيرى بر رشد اقتصادى

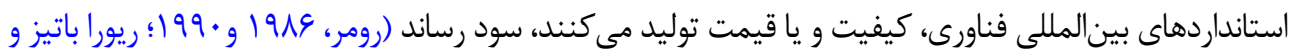

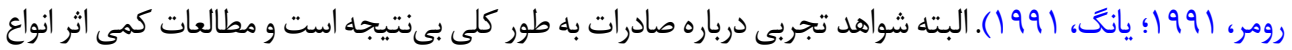

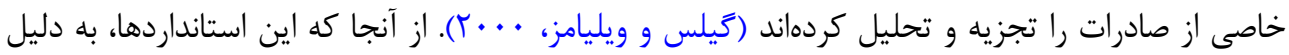

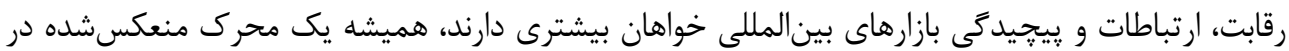

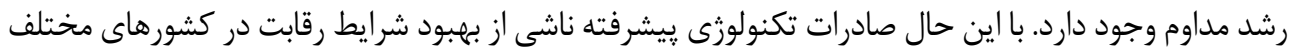

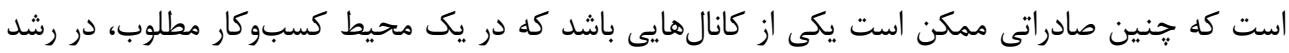
اقتصادى بالاتر منعكس شده است

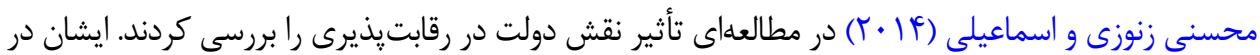

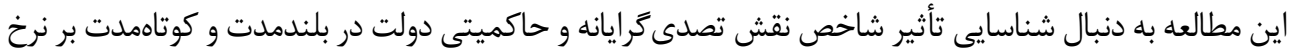

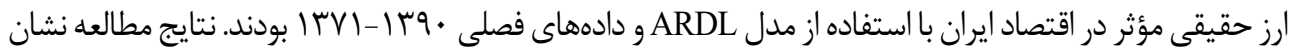

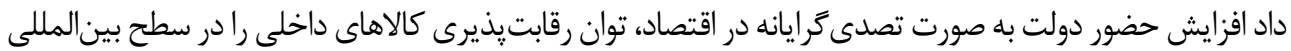

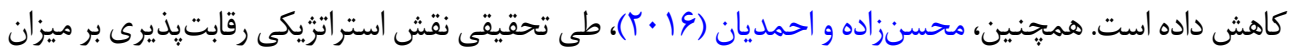

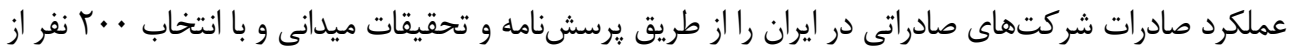

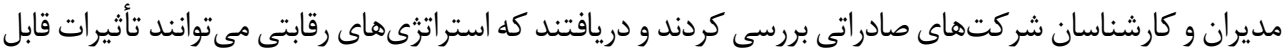
توجهى بر ميزان عملكرد صادرات داشته باشند.

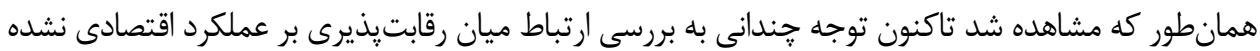

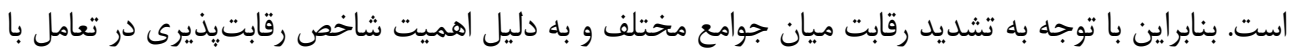

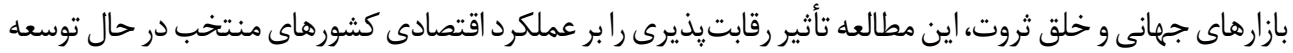

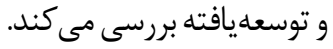




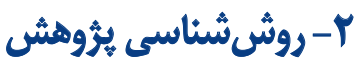

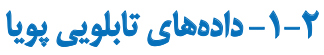

در بسيارى از مواقع، محققان اقتصادى به دنبال بررسى يويايى در روابط اقتصادى هستند. بنابر اين در روشهاى مختلف

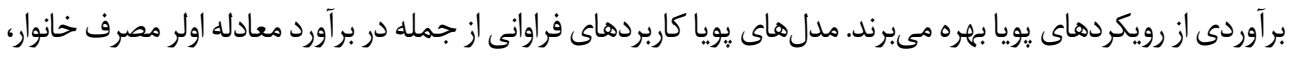

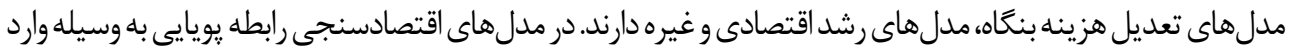

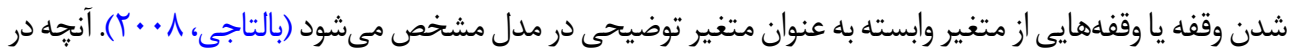

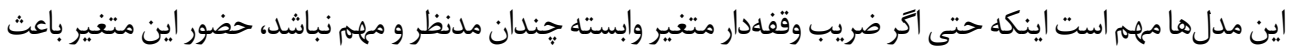

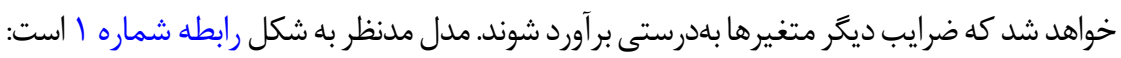

$$
y_{i t}=p y_{i, t-1}+x_{i t}^{\prime} \beta+\alpha_{i}+\varepsilon_{i t}
$$

روش استفادهشده، روش گشتاورهاى تعميميافته است. اين روش بلهدستآوردن متغيرهاى ساز زار، نيازمند تعداد

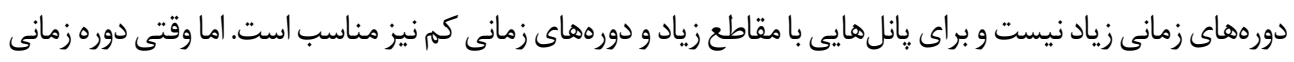

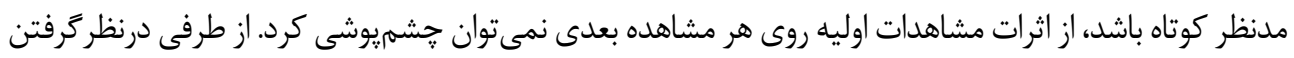

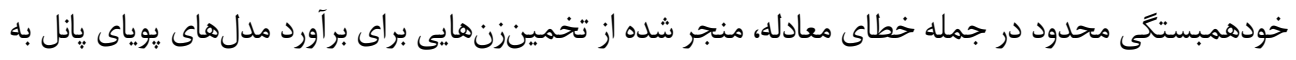

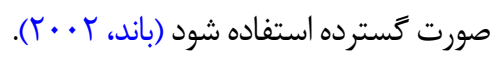
㑭

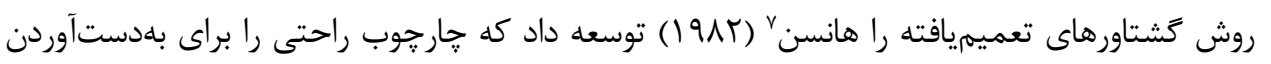

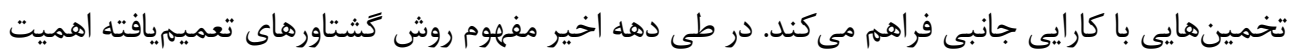

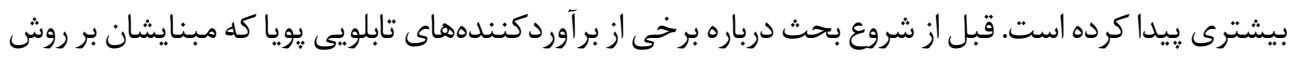

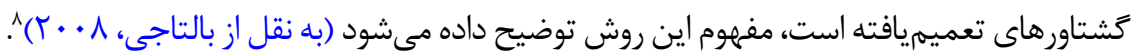

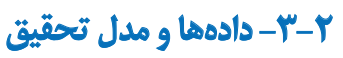

با توجه به ماهيت دادهاى تحقيق، روش استفادهده براى برآورد معادله رگرسيونى، مدل رگرسيونى مربوط

\section{Hansen}

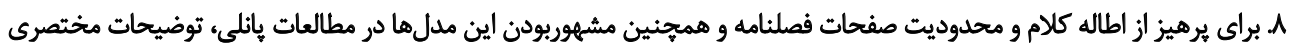

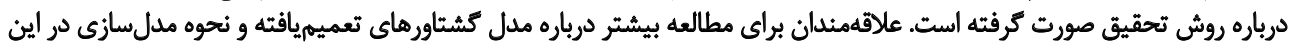

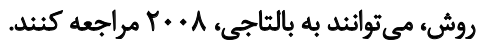




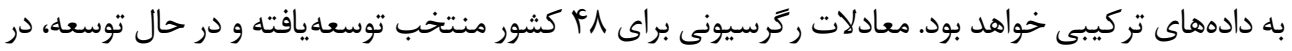

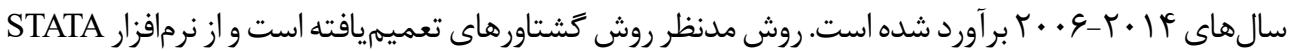

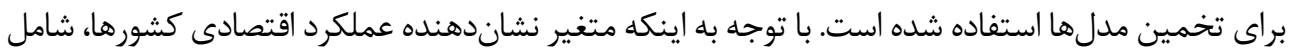

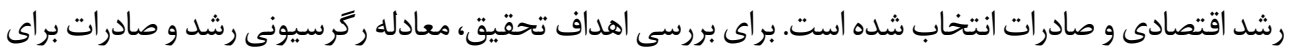

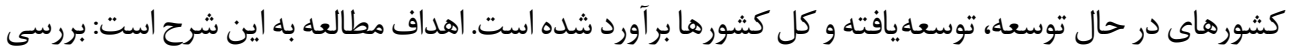

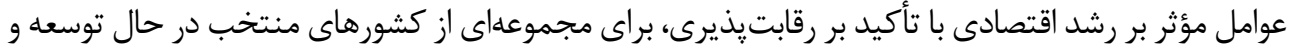

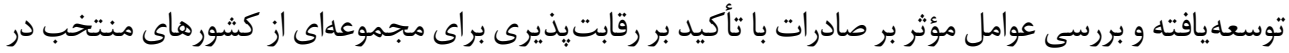

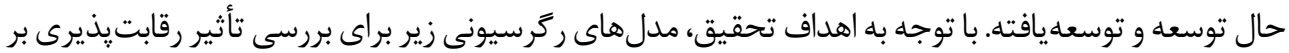
رشد اقتصادى برآورد شده است:

$\lg d p_{i t}=\alpha_{1}+\beta_{1} i c o_{i t}+\beta_{2} c g d p_{i t}+\beta_{3} h s e_{i t}+\beta_{4} i n f_{i t}+\beta_{5} l f c_{i t}+u_{i t}$

كه در رابطه شماره r مذكور داريم: lgdp: لكاريتم توليد سرانه؛ ico: شاخص بين المللى رقابت زيذيرى؛ cgdp:

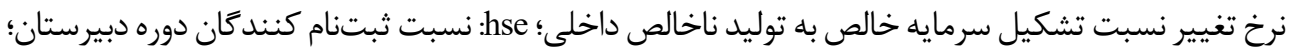

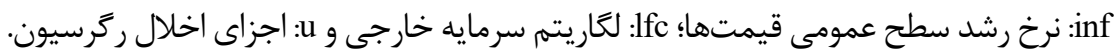
مدل مذكور براى كشورهاى در حال توسعه و توسعهيافته برآورد شده است و معادله ركرسيون براى مجموع

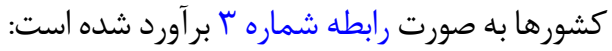

$$
\operatorname{lgd} p_{i t}=\alpha_{2}+\lambda_{1} i c o_{i t}+\lambda_{2} c g d p_{i t}+\lambda_{3} h s e+\lambda_{4} i n f_{i t}+\lambda_{5} l f c_{i t}+\lambda_{6} d u m+v_{i t}
$$

در معادله مذكور تمامى موارد مطابق معادله قبلى است و نشاندهنده متغير دامى است كه براى كشورهاى

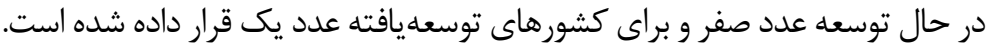

مدل بر آوردشده براى بررسى فرضيه تأثير رقابتيذيرى بر صادرات به اين رابطه هاى شماره أ و ه است: r

$$
l e x_{i t}=\alpha_{3}+\phi_{1} i c o_{i t}+\phi_{2} \lg e_{i t}+\phi_{3} e_{i t}+Z_{i t}
$$

$$
\text { lex }=\alpha_{4}+\gamma_{1} i c o_{i t}+\gamma_{2} \lg e_{i t}+\gamma_{3} e r_{i t}+\gamma_{4} \text { infgdp } p_{i t}+\varepsilon_{i t}
$$

كه در اين معادلات داريم: lex: لعًاريتم صادرات كالاها و خدمات فاوا؛ ico: رقابتيذيرى؛ lge: لكاريتم مخارج مصرفى دولت؛ infgdp: تورم محاسبهشده از شاخص قيمت تعديل كننده توليد داخلى؛ er: نرخ ارز و ع, Z: اجزاى 
اخلال ركرسيونها.

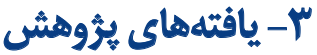

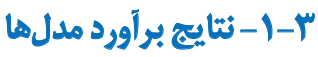

از جمله روش هاى اقتصادسنجى مناسب براى حل يا كاهش مشكل درونزابودن متغيرها، استفاده از روش

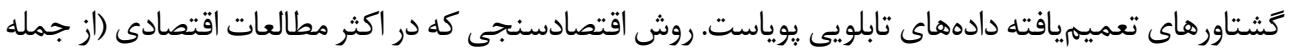

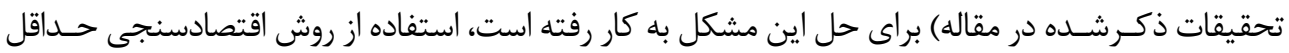

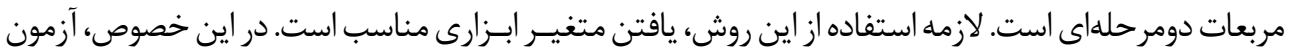

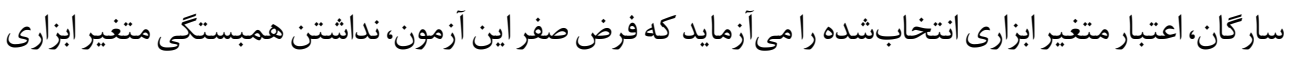

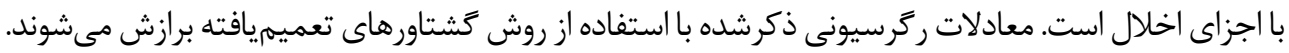

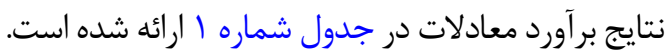

علاوه بر متغير رقابتيذيرى، متغيرهاى رشد سرمايه، نسبت ثبتنامشد

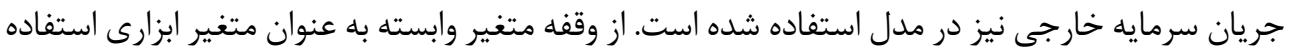

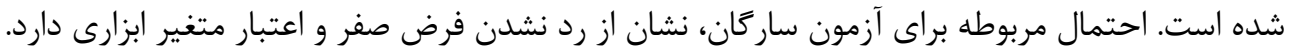

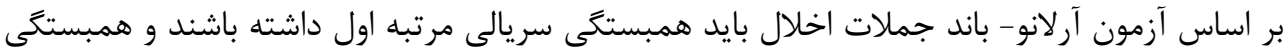

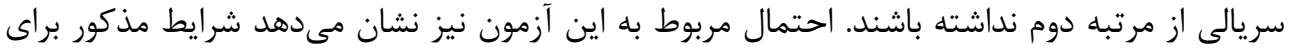

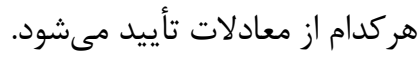

آزمون والد براى اين معادله ركرسيون حاكى از معنى دارى كل رگرسيون است. ضريب متغير رقابت ٍذيرى

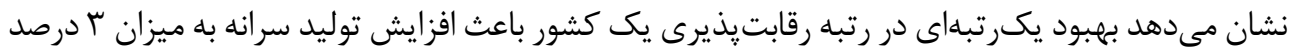

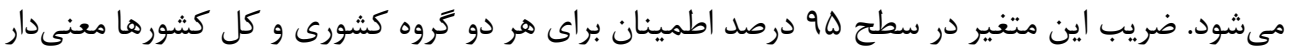

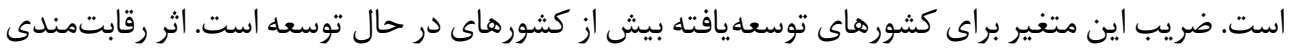

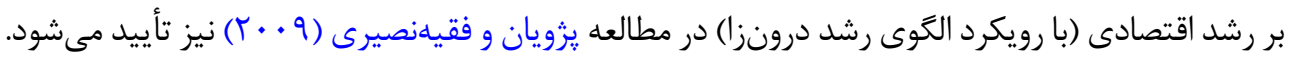

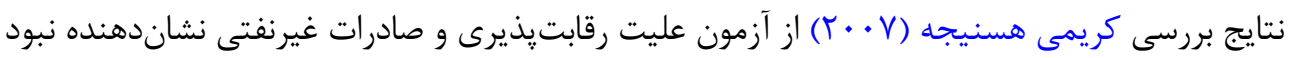

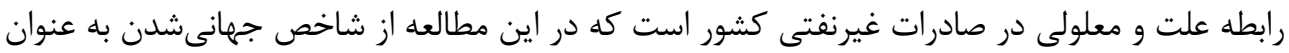
شاخص رقابت يذيرى استفاده شده بود.

تأثير متغير رشد سرمايه نيز بر لعاريتم توليد سرانه مثبت و معنى دار است است كه با انتظارات تئوريك نيز

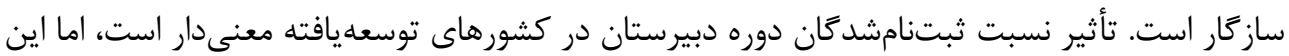

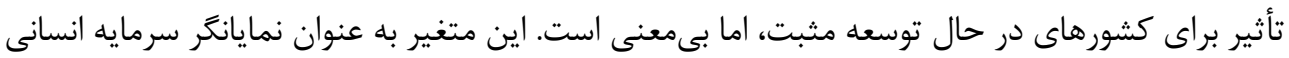

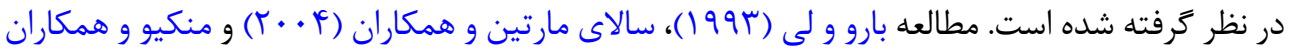

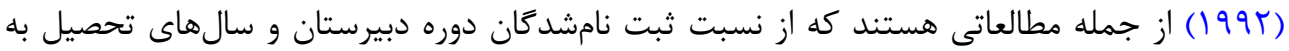


عنوان متغير نشاندهنده سرمايه انسانى استفاده كردهاند.

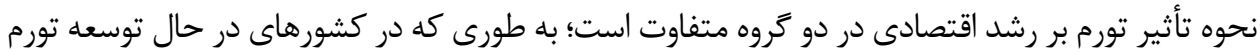

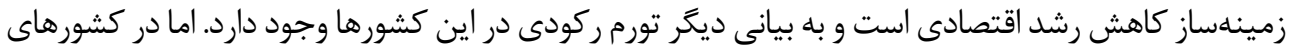

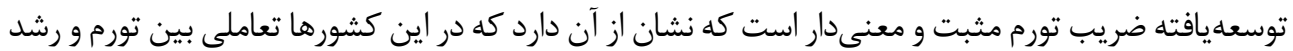

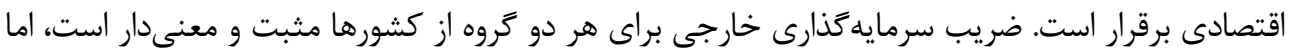

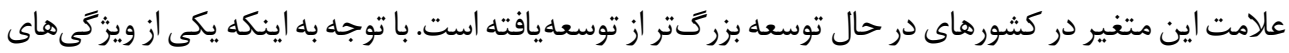

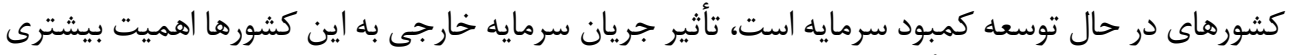
دارد. نتايج نيز اين موضوع رال توسعه كأييد مي كنمايد.

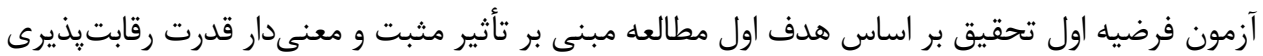

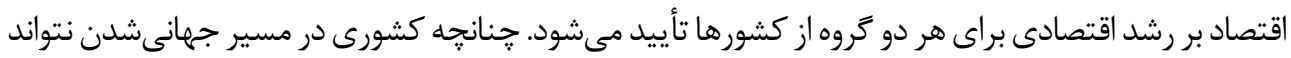

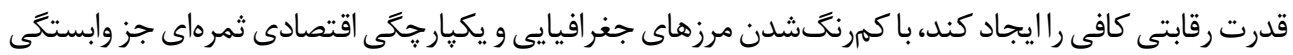

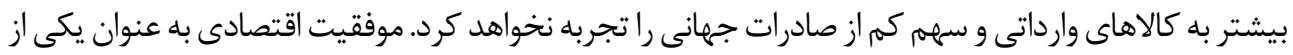

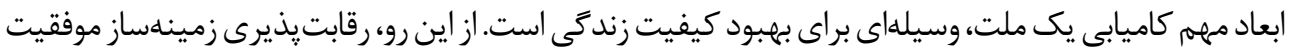

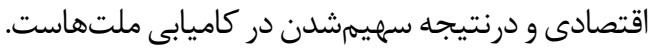

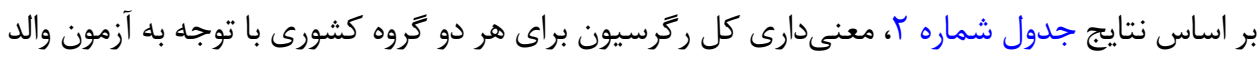

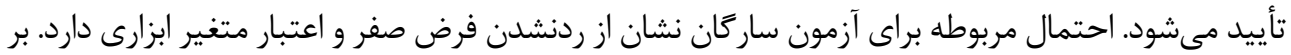

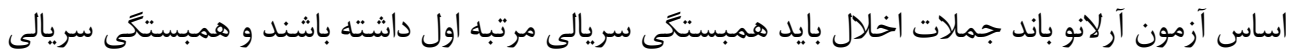

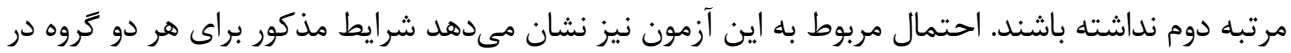

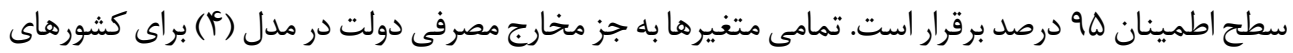

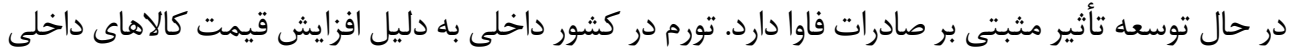

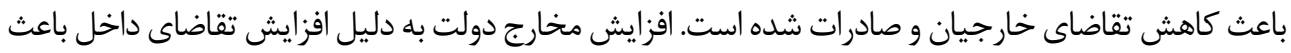

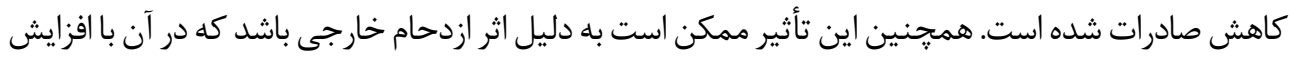

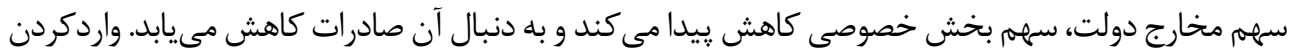

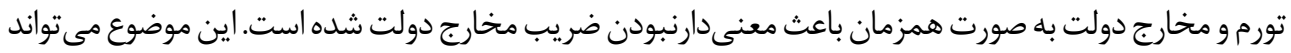

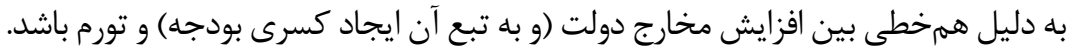

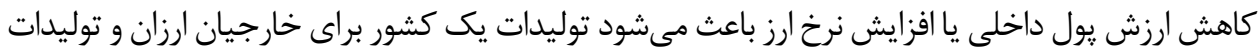

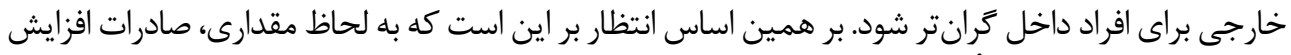

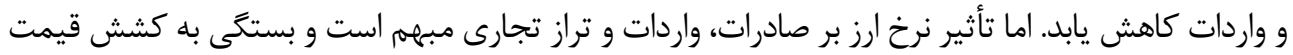

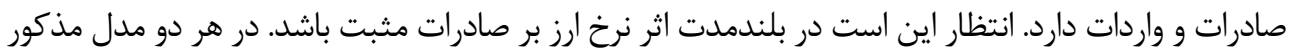
اين تأثير معنى وار و مثبت بودات وارده استظار اين است

اثر رقابتيذيرى بر صادرات فاوا نيز مثبت ودر سطح اطمينان له درصد براى مدل (4) و در سطح اطمينان •9 درصد براى مدل 
جدول ا. نتايج برآورد معادلات ركرسيونى

\begin{tabular}{|c|c|c|c|c|c|c|}
\hline \multicolumn{2}{|c|}{ كل كشيوروها } & \multicolumn{2}{|c|}{ كشور هاي مر حال توسعه } & \multicolumn{2}{|c|}{ كشبور هائ توسعه يافتته } & \multirow{2}{*}{ آيتم } \\
\hline الحتمال & ضريب & الجتمال & ضريب & المتمال & ضريب & \\
\hline$+1+\infty$ & $\mid / 41$ & .1111 & $\cdot / r V A$ & $+1++$ & WV & عرض از مبدا \\
\hline 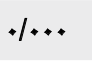 & $+|\pi|$ & $\%$ &.$/ 9 r 8$ & $\%$ & $+|A|$ & $\operatorname{lgdp}(-1)$ \\
\hline$+1+\infty$ & $+1+V A$ & $\%$ & $\cdot 1 \cdot v e$ & $\%$ & $+1+m$ & ico \\
\hline$+\ldots$ & $+1+* r$ & $.1+\ldots$ & .1 .19 & $\%$ & . r.rir & cgdp \\
\hline $.1 \cdot \mathrm{rg}$ & $.10 .+18$ & .18 & $.1 . . . r \Delta$ & $.1 \cdot 17$ & $.10 .+17$ & hse \\
\hline. Mre &.$- / \cdot \cdot r$ & $.1 \cdots$ &.$- / . . r$ & $.1 .$. & $.10 .19 \mathrm{~V}$ & inf \\
\hline $.1 . .1$ & .1 .01 & $.1 \cdot .1$ & $.1 . .8$ & $\%$ & $.1 . .0 \Delta 1$ & Ifc \\
\hline$\%$ & $1 / \cdot 1$ & - & - & - & - & dum \\
\hline .1198 & melit & .199 & $1.1 \cdot v$ & .180 & $r P / \Delta$ & آزمون ساركان \\
\hline $.1+$ & ArATY & .10. & ralf &.$\ldots$ & rons. & أزمون والد \\
\hline $\begin{array}{l}.1 \cdot{ }^{\circ} \\
. M W\end{array}$ & $\begin{array}{l}\text { Order I } \\
\text { Order Y }\end{array}$ & $\begin{array}{l}.1 \cdot 88 \\
. / 174\end{array}$ & $\begin{array}{l}\text { Order } 1 \\
\text { Order Y }\end{array}$ & $\begin{array}{l}11 . \\
. / 49\end{array}$ & $\begin{array}{l}\text { Order I } \\
\text { Order Y }\end{array}$ & Arellano-Bond \\
\hline \multicolumn{2}{|c|}{ TAT } & \multicolumn{2}{|c|}{$n$} & \multicolumn{2}{|c|}{$\mathrm{M}$. } & ت تعداد مشاهدات \\
\hline \multicolumn{2}{|c|}{ rf } & \multicolumn{2}{|c|}{ if } & \multicolumn{2}{|c|}{ r. } & تعلاد كشورها \\
\hline
\end{tabular}

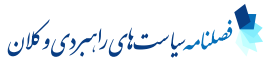

مئبع: يافتهاى تحقيق

(ه) معنى (هار است. بنابر اين آزمون فرضيه دوم نيز برقرارى تأثير رقابتيذيرى بر صادرات در كشورها در حال توسعه را تأييد مى كند.

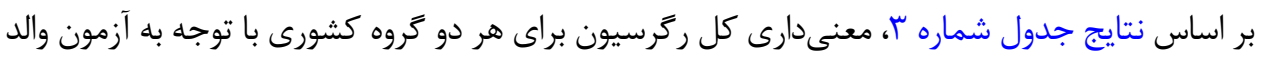

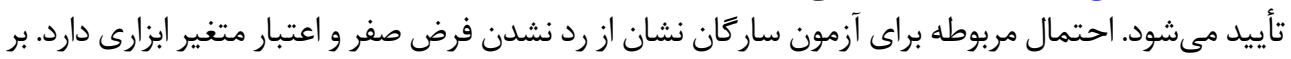

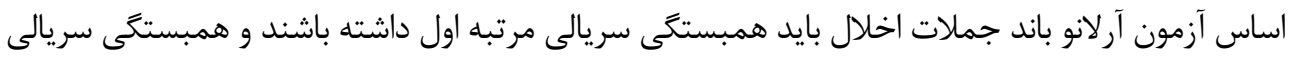

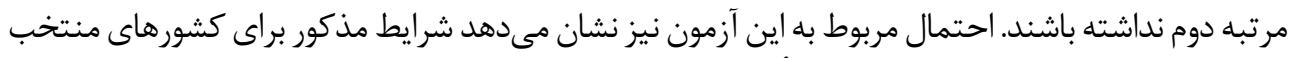

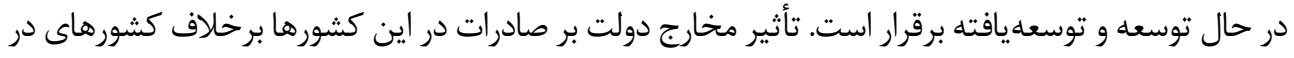

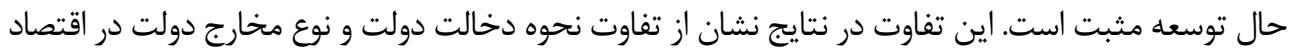

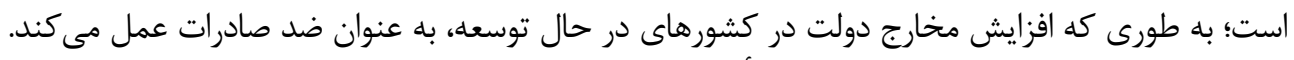

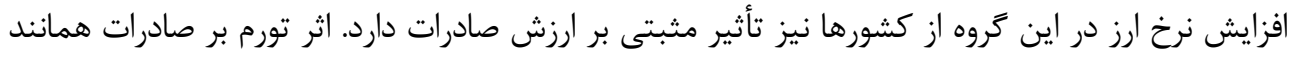

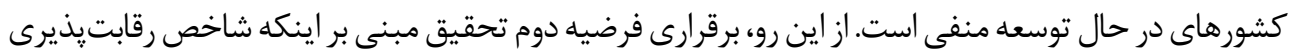

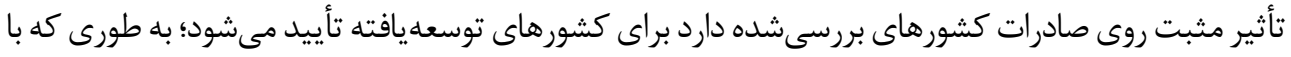


جدول r. ركرسيون صادرات فاوا (كشورهاى در حال توسعه)

\begin{tabular}{|c|c|c|c|c|}
\hline \multicolumn{2}{|c|}{ هدل (0) } & \multicolumn{2}{|c|}{ مدلر(E) } & \multirow{2}{*}{ آيتم } \\
\hline احتمال & ضريب & الحتمال & ضريب & \\
\hline$+10+\infty$ & $-+/ 897$ & $+1+\infty$ & $-V / \Delta V$ & عرض ازز مبلا \\
\hline.$\ldots$ &.$/ 8 V$ & $\%$ &.$/ \& \Delta$ & $\operatorname{lex}(-1)$ \\
\hline .10. & . NIF & $.10+\infty$ &.$/ 499$ & ico \\
\hline$\%$ & $-+1 \cdot 11$ & .1. &.$- / 1199$ & lge \\
\hline $.1 \cdot T E$ & 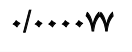 & $.1 \cdot 18$ & $.10 .+r^{f}$ & er \\
\hline (ME & $-.1 \cdot 18$ & - & - & infgdp \\
\hline .1198 & $10 / 8$ & . $/ 9 T$ & $18 / \Delta$ & آزّهون ساركان \\
\hline $.1 \ldots$ & TrETI & 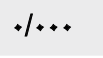 & $\Delta \cdot V$. & آزمون والد \\
\hline$\cdot 1 \cdot W$ & Order 1 & I.r & Order 1 & Arellano-Bond \\
\hline \multirow[t]{3}{*}{.$/ 4 q$} & OrderY & .180 & Orderr & \\
\hline & $n$ & \multicolumn{2}{|c|}{ IrA } & تعداد مشاهلات \\
\hline & if & \multicolumn{2}{|c|}{19} & تعداد كشورها \\
\hline
\end{tabular}

بهبود شرايط رقابت يذيرى بين المللى صادرات كالاها و خدمات فاوا افزايش ييدا مى كند. "Y-Y- بروسى تصويرى رابطه ميان رقابثيذيرى با رشد اقتصادى و صادرات

براى اينكه بتوان تصوير ملموسترى از رابطه بين رقابتيذيرى و عملكرد اقتصادى به دست آورد و همجنين

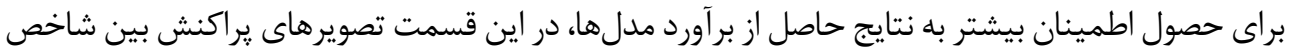

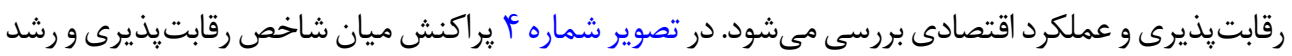

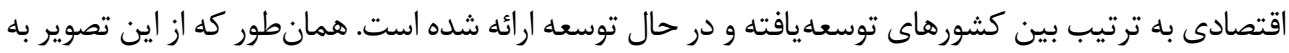

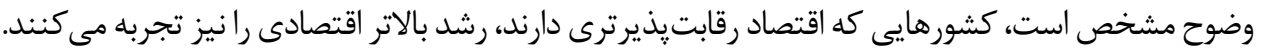

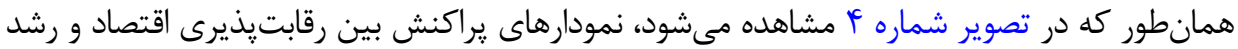

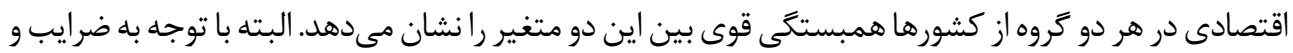

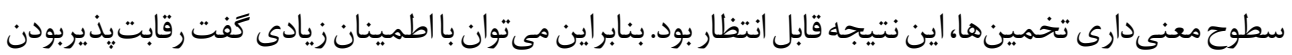

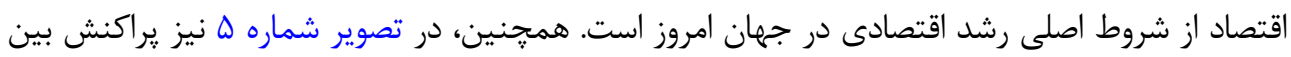

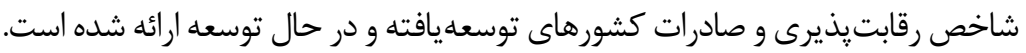


جدول ب. ركرسيون صادرات فاوا (كشورهاى ثوسعهيافته)

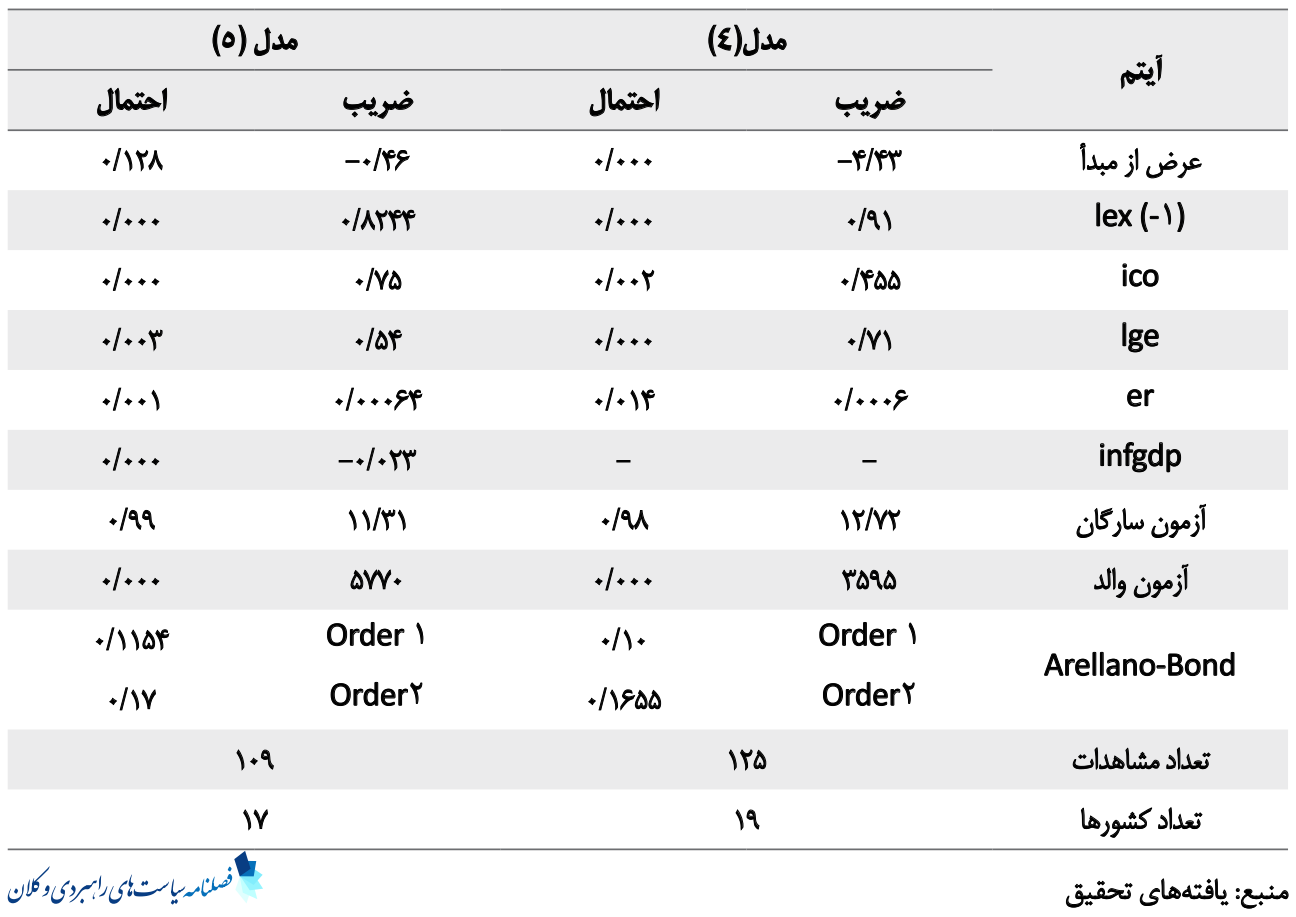

نتايج اين نمودارهاى موجود در اين تصوير حاكى از اين است كه كشورهايى كه شاخص رقابت يذيرى بهترى

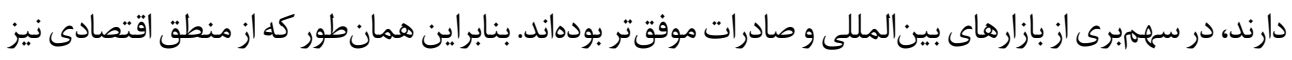

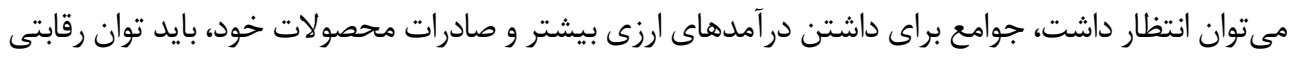

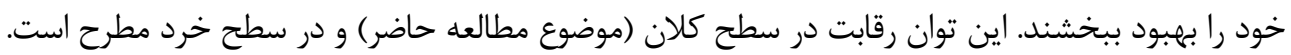

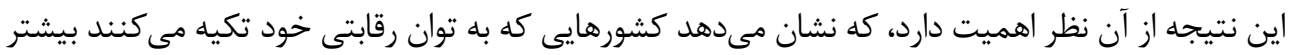
از كشورهايى كه به منابع طبيعى و خام براى صادرات وابستهاند. در صادرات محصولات خود موفقتر هستند

\section{ع- بحث و ثتيجلئيرى}

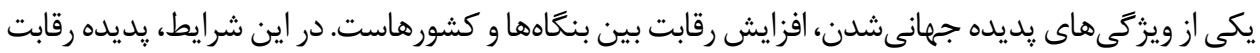

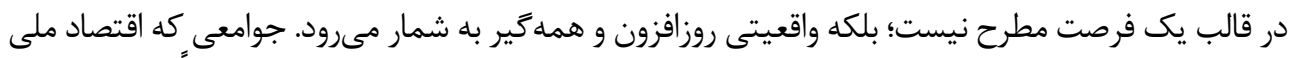

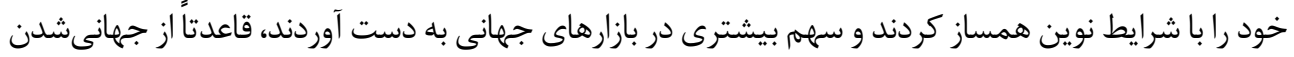

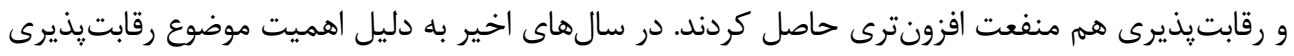

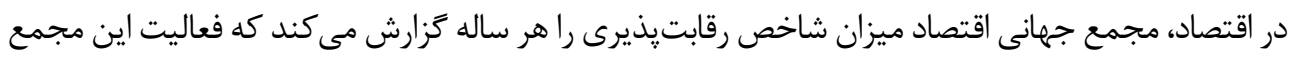


كشورهاي نر حال توسعه

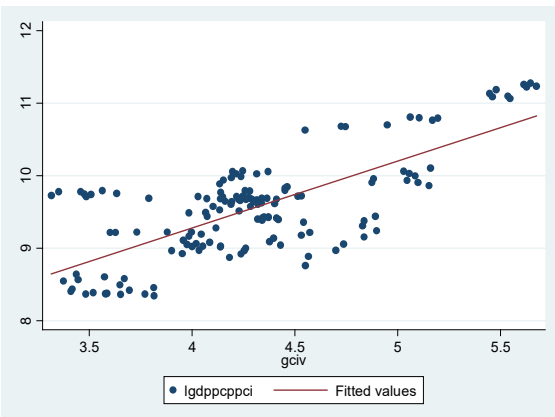

كشورهاي تونعليافئه

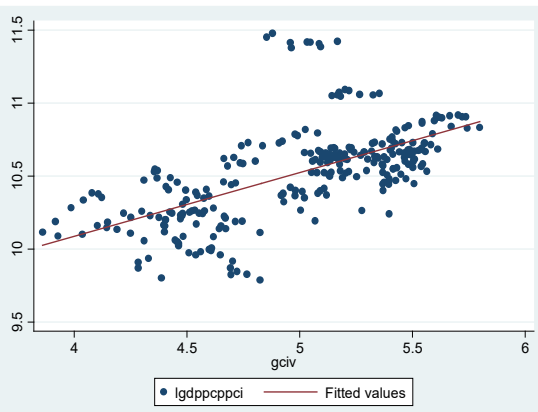

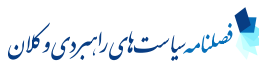

تصوير F. نمودار براكنش رابطه رقابتيذيرى و رشد اقتصادى در كشورهاي توسعهيافته ودر حال توسعه

از سال \& • . r شروع شده است. از اين رو، مطالعه حاضر تأثير رقابتيذيرى بر عملكرد اقتصادى در كشورهاى

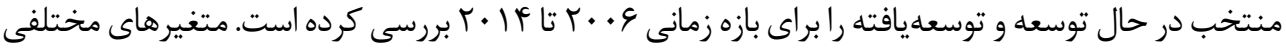

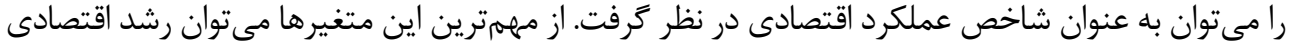

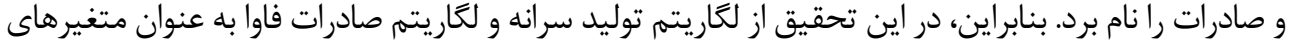

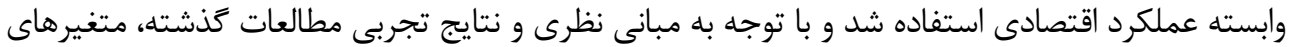

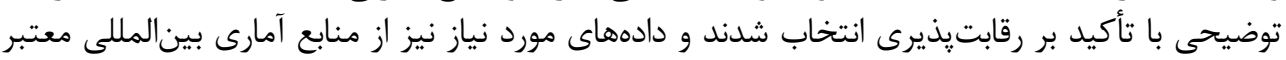
جمع آورى شد.

متغير هاى استفادشده در معادله، رشد اقتصادى شامل رقابت يذيرى، نرخ تغيير نسبت تشكيل سرمايه خالص

كشورهاي در حال توتسع d

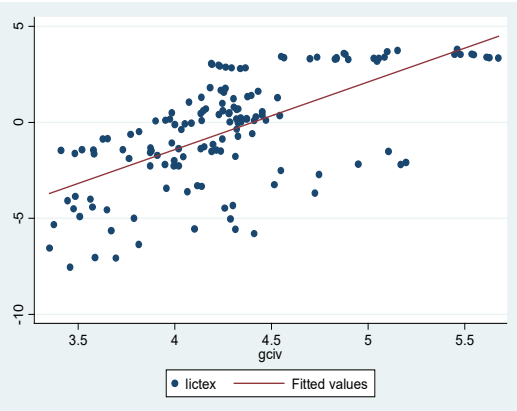

كشورهاي توسعهيافته

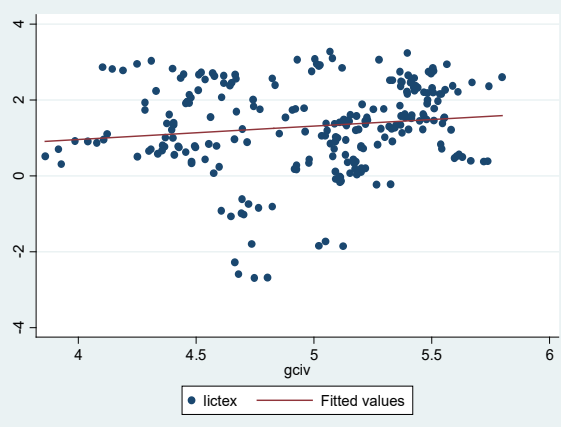

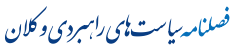

تصوير هـ نمودار براكنش رقابثيذيرى و لكاريتهم صادرات فاوا در كشورهاى در حال توسعه و توسعليافته (منبع: يافتههاى تحقيق) 
به توليد ناخالص داخلى، نسبت ثبتنام كنندكان دوره دبيرستان و نرخ رشد سطح عمومى قيمتها هستند.

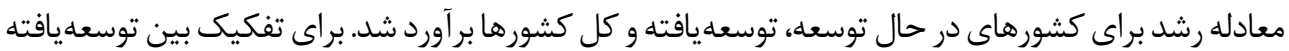

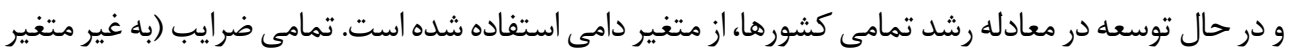

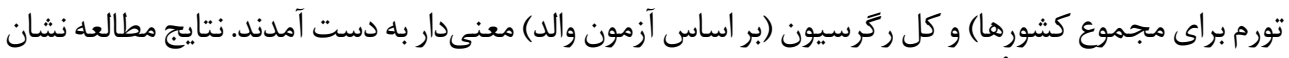

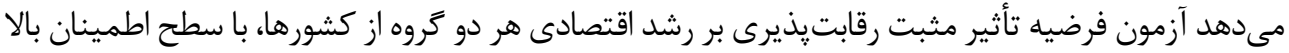

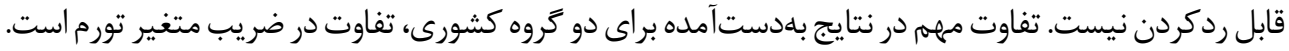

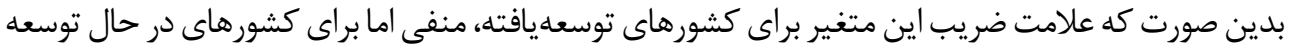

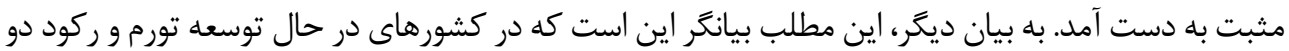

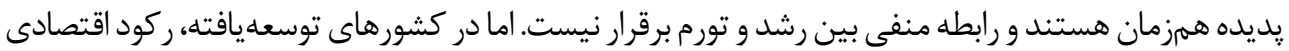
با كاهش سطح عمومى قيمتها همراه است.

در بخش دوم از برآورد معادلات رگرسيونى، لكاريتم صادرات فاوا به عنوان متغير وابسته در نظر گرفته شد.

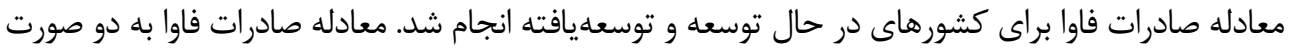

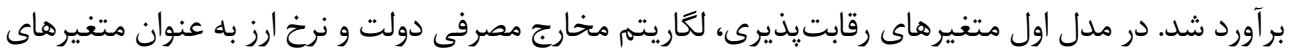

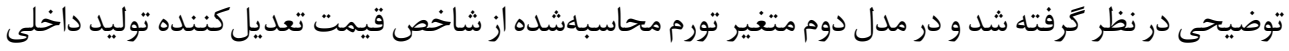

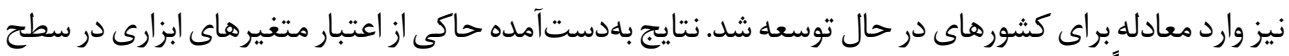

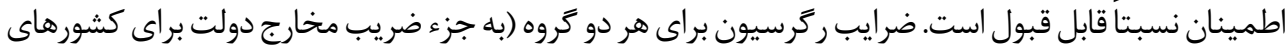

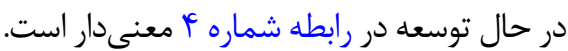

آزمون والد نيز معنى دارى كل رگرسيون را براى حالتهاى مختلف و هر دو گروه كشورى تأييد مى كند.

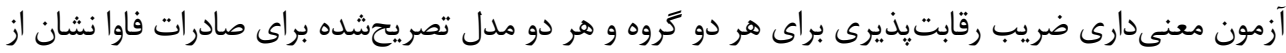

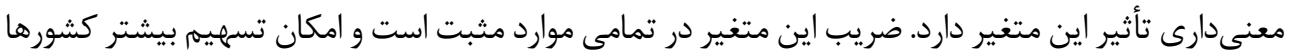

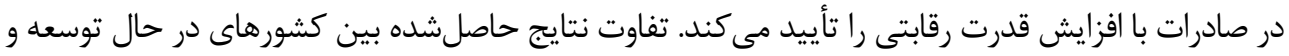

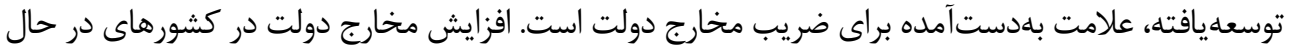

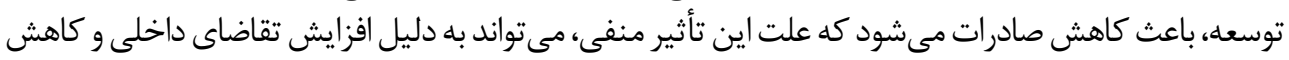

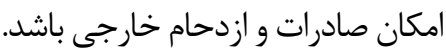

با توجه به نتايج تحقيق، ييشنهادات در ادامه ارائه مىشود: شناخت عوامل مؤثر بر جايگاه نامناسب اقتصاد

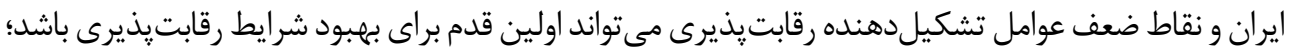

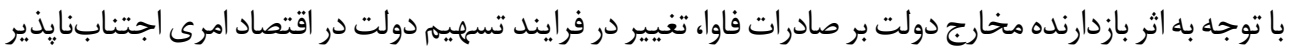

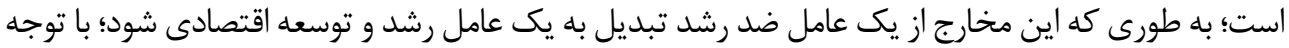

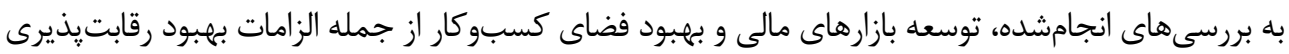

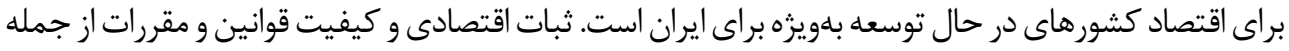

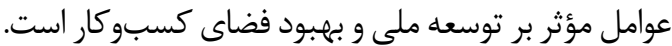




\section{ملاحظات اخلاقى}

يبيروى از اصول اخلاق بوثوهش

همه اصول اخلاق در يزوهش حاضر رعايت شده است.

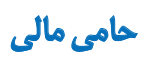

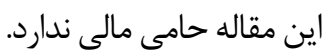

مشاركثنويسئدكان

تعارض مناف نويسندكان در آمادهسازى اين مقاله شركت كردهاند.

بنابر اظهار نويسندًان، اين مقاله تعارض منافع ندارد. 


\section{References}

Acemoglu, D., Johnson, S., \& Robinson, J. A. (2002). Reversal of fortune: Geography and institutions in the making of the modern world income distribution. The Quarterly Journal of Economics, 117(4), 1231-94. [DOI:10.1162/003355302320935025]

Arruda, C. A., Araújo, M. S., Rios, J. F., \& Silveira, F. P. (2009). [The relationship between economic growth and competitiveness: A study of the prediction capacity of the global competitiveness Report (Portuguese)]. BASE-Revista de Administração e Contabilidade da Unisinos, 6(4), 285-98. [DOI:10.4013/base.2009.64.01]

Baltagi, B. (2008). Econometric analysis of panel data. Hoboken: John Wiley \& Sons.

Barro, R. J., \& Lee, J. W. (1993). International comparisons of educational attainment. Journal of Monetary Economics, 32(3), 36394. [DOI:10.1016/0304-3932(93)90023-9]

Beheshti, M. B. (2010). [Iranian economic development (Persian)]. Tabriz: University of Tabriz.

Ben Amar, M., \& Hamdi, M. T. (2012). Global competitiveness and economic growth: Empirical verification for African countries. International Journal of Economics and Finance, 4(6), 125-31. [DOI:10.5539/ijef.v4n6p125]

Blundell, R., \& Bond, S. (1998). Initial conditions and moment restrictions in dynamic panel data models. Journal of Econometrics, 87(1), 115-43. [DOI:10.1016/S0304-4076(98)00009-8]

Bond, S. R. (2002). Dynamic panel data models: A guide to micro data methods and practice. Portuguese Economic Journal, 1(2), 141-62. [DOI:10.1007/s10258-002-0009-9]

Boschma, R. (2004). Competitiveness of regions from an evolutionary perspective. Regional Studies, 38(9), 1001-14. [DOI:10.108 0/0034340042000292601]

Calderón, C., \& Servén, L. (2004). The effects of infrastructure development on growth and income distribution. Washington: The World Bank. [DOI:10.1596/1813-9450-3400]

Canning, D., \& Pedroni, P. (1999). Infrastructure and long run economic growth. London: Center for Analytical Economics working paper.

Cazacu, A. M. (2015). Global Competitiveness Index and economic growth. Paper presented in: International Finance and Banking Conference, Bucharest, Romania, 1-5 May 2015.

Chung, S. (2010). Innovation, competitiveness, and growth: Korean experiences. Annual World Bank Conference on Development Economics, 17(1), 333-75.

Delgado, M., Ketels, C., Porter, M. E., \& Stern, S. (2012). The determinants of national competitiveness. National Bureau of Economic Research, 12(47), 1-47. [DOI:10.3386/w18249]

Giles, J. A., \& Williams, C. L. (2000). Export-led growth: A survey of the empirical literature and some non-causality results. Part 1. The Journal of International Trade \& Economic Development, 9(3), 261-337. [DOI:10.1080/09638190050086177]

Karimi Hosnijeh, H. (2007). [Globalization, competitive and nonoil export promotion: Analysis of causality in Iran economy (Persian)]. Quarterly Journal of Quantitative Economics, 4(1), 117-34.

Kordalska, A., \& Olczyk, M. (2016). Global Competitiveness and Economic Growth: A One-Way or Two-Way Relationship? Equilibrium. Quarterly Journal of Economics and Economic Policy, 11(1), 121-42. [DOI:10.12775/EQUIL.2016.006]

Mankiw, N. G., Romer, D., \& Weil, D. N. (1992). A contribution to the empirics of economic growth. The Quarterly Journal of Economics, 107(2), 407-37. [DOI:10.2307/2118477] 
Mirahsani, M. (2013). [Indicators of competitiveness of Iran and some countries of the world from the perspective of the World Economic Forum report (2014-2013) (Persian)]. Economic Journal, 9-10, 128-07.

Mohebi, M., Khazaei Poul, A. (2014). [Green growth and its solutions for small and medium enterprises (Persian)]. Paper presented at: Second National Conference on Entrepreneurship and Competitiveness, Babolsar, Iran, 21 May 2014.

Mohseni Zonozi, S. J., Esmaeili, S. M. (2014). [The effect of state's role in competitiveness (Persian)]. Quarterly Journal of the Macro and Strategic Policies, 2(5), 41-65.

Mohsenzadeh, M., \& Ahmadian, S. (2016). The mediating role of competitive strategies in the effect of firm competencies and export performance. Procedia Economics and Finance, 36, 456-66. [DOI:10.1016/S2212-5671(16)30069-7]

North, D. C. (1989). Institutions and economic growth: An historical introduction. World Development, 17(9), 1319-32.

Palei, T. (2015). Assessing the impact of infrastructure on economic growth and global competitiveness. Procedia Economics and Finance, 23, 168-75. [DOI:10.1016/S2212-5671(15)00322-6]

Pejouyan, J., \& Faghih Nasiri, M. (2009). [Competitive effect on economic growth with endogenous growth pattern approach (Persian)]. Economic Researches of Iran, 13(38), 132-97.

Petrariu, I. R., Bumbac, R., \& Ciobanu, R. (2013). Innovation: A path to competitiveness and economic growth: The case of CEE countries. Theoretical \& Applied Economics, 5(582), 15-26.

Porter, M. (1990). The competitive advantage of nation's. Harvard Business Review, 68, 73-93. [DOI:10.1007/978-1-349-11336-1]

Rivera-Batiz, L. A., \& Romer, P. M. (1991). Economic integration and endogenous growth. The Quarterly Journal of Economics, 106(2), 531-55. [DOI:10.2307/2937946]

Rodrik, D., Subramanian, A., \& Trebbi, F. (2004). Institutions rule: the primacy of institutions over geography and integration in economic development. Journal of Economic Growth, 9(2), 131-165.

Romer, P. M. (1986). Increasing returns and long-run growth. Journal of Political Economy, 94(5), 1002-37. [DOI:10.1086/261420]

Romer,P.M.(1990). Endogenous technological change. Journal of PoliticalEconomy, 98(5.Part2), S71-S102. [DOI:10.1086/261725]

Roodman, D. (2006). How to do xtabond2: An introduction to difference and system GMM in Stata. Washington: Center for Global Development. [DOI:10.2139/ssrn.982943]

Rostow, W. W., \& Rostow, W. W. (1990). The stages of economic growth: A non-communist manifesto. Cambridge: Cambridge university press. [DOI:10.1017/CBO9780511625824]

Shahiki Tash, M. N., Mahmodpour, K., \& Mohseni, H. (2016). [A survey of affecting factors on the countries competitiveness with emphasis on Iran economy (Persian)]. Quarterly Journal of Fiscal and Economic Policies, 3(11), 155-88.

Sala-i-Martin, X., Doppelhofer, G., \& Miller, R. I. (2004). Determinants of long-term growth: A Bayesian Averaging of Classical Estimates (BACE) approach. American Economic Review, 94(4), 813-35. [DOI:10.1257/0002828042002570]

Sanfey, P., \& Zeh, S. U. (2012). Making sense of competitiveness indicators in south-eastern Europe. London: European Bank for Reconstruction and Development.

Vares, H., Mohammadi, Sh., Parvandi, Y. (2012). [On economic prosperity: Providing a model for improving national competetiveness of Iran (Persian)]. Iranian Journal of Management Sciences, 7(26), 25-48.

Young, A. (1991). Learning by doing and the dynamic effects of international trade. The Quarterly Journal of Economics, 106(2), 369-405. [DOI:10.2307/2937942] 